\title{
An Absorbed Dose Water Calorimeter: Theory, Design, and Performance*
}

\author{
Steve R. Domen * * \\ National Bureau of Standards, Washington, D.C. 20234 \\ January 13, 1982
}

\begin{abstract}
Two calibrated thermistors sandwiched between two insulative polyethylene films were immersed in a $30 \mathrm{~cm}$ cube of water having a low thermal diffusivity. The product of the specific heat of water and temperature rise gave the combined effect of the local absorbed dose and any heat defect at a position along a temperature profile produced by cobalt 60 irradiation. The dose rate was near $18 \mathrm{mGy} / \mathrm{s}$ and exposure times were $3 \mathrm{~min}$. The standard deviation for a daily set of measurements was about 0.6 percent. Calculations showed that conductive heat transfer produced a negligible effect at the position of measurement along the beam axis. Tests showed the absence of convection.

Temperature drifts before irradiation were quickly controlled by changing the power dissipated in the water between two immersed electrodes. Reproducible measurements were obtained in distilled water supplies that had a wide range of impurities. Measurements, after saturating the water with nitrogen or oxygen, showed no difference. A difference of 0.6 percent would have been easily detectable. Tests with several chemicals added to water showed some unexpected results and changes in the measured absorbed dose rate versus accumulated dose. The measured absorbed dose rate in distilled water under the conditions described was 3.5 percent higher than that determined from measurements with a graphite calorimeter.
\end{abstract}

Key words: absorbed dose; calorimeter; convection; heat defect; radiation chemistry; thermistor; water.

\section{Contents}

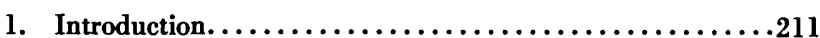

2. Measurement Theory ........................ 212

2.1 Measurement...........................

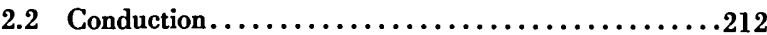

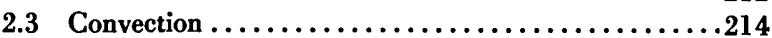

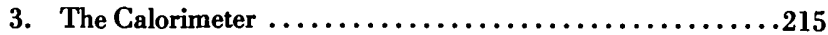

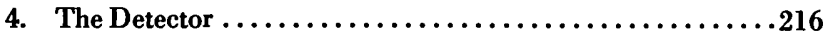

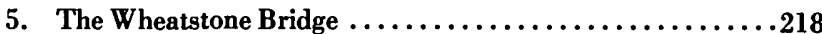

6. Thermistor Sensitivity Measurements. ............219

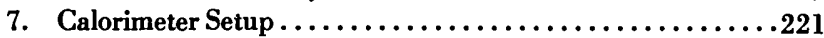

8. Temperature Drift Control. ..................221

\section{Introduction}

The purpose of this paper is to describe an improved model of an absorbed dose $^{1}$ water calorimeter previously reported [1]. ${ }^{2}$ Many features of the present improved

\footnotetext{
*Some initial work was supported in part by the National Cancer Institute, National Institute of Health, Bethesda, Md.

**Center for Radiation Research, National Measurement Laboratory.

${ }^{1}$ Absorbed dose is the mean energy per unit mass imparted to matter by ionizing radiation. The SI unit of absorbed dose is the gray (symbol Gy). $1 \mathrm{~Gy}=1$ J/kg.

${ }^{2}$ Figures in brackets indicate literature references at the end of this paper.
}

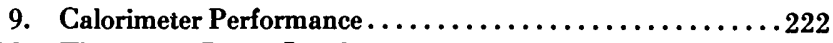

10. Thermistor Power Levels ........................ 224

11. Tests in the $\mathrm{C}, \mathrm{J}$, and $\mathrm{C}+\mathrm{J}$ Modes..............226

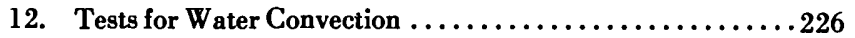

13. Effects of $\mathrm{N}_{2}$ and $\mathrm{O}_{2}$ Saturated $W$ ater. . . . . . . . . . 229

14. Effects of Water Impurities .....................229

15. Results of Collimated Beam.................... 232

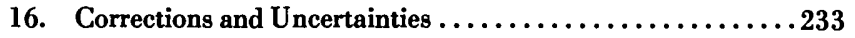

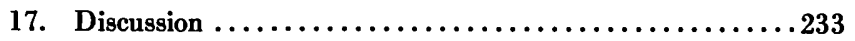

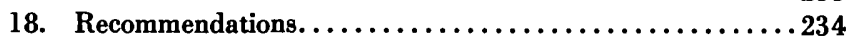

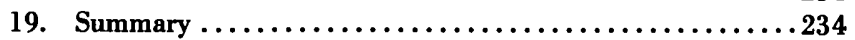

model that includes a unique and simple method for quickly bringing temperature drifts under control are described in a U.S. patent [2]. Those features will be described here in further detail along with results of investigations, tests, and experimental measurements. This work was described briefly [3] and in its entirety [4].

The calorimeter is unique in several respects, one being that for the first time measurements of an abzorbed dose profile can be derived from measurements of temperature rises at points along a temperature profile in a large continuous water medium. The intention of this 
simple method is to circumvent indirect measurements in other materials (with spectral-sensitive detectors such as ionization chambers) and numerous correction factors to convert those measurements to water which is the standard reference material [5]. A direct measurement in water would then also circumvent any required knowledge of the incident spectrum which is too often not well-known but must be estimated and used in timeconsuming calculations when indirect measurements are made. The calorimeter also circumvents another problem that appears too complicated to resolve: the effect of vacuum gaps around calorimetric bodies made of solid material. That effect would be extremely difficult to evaluate experimentally or theoretically for the numerous incident radiation and scattering patterns throughout the medium $[1,6]$. The problem is further complicated because gaps of varying sizes are made by different experimenters. This paper describes an absorbed dose calorimeter that has no gaps.

A workable absorbed dose water calorimeter would be a valuable tool in the medical and radiation chemistry fields, but there appears to have been no investigation, report, attempt, or even serious discussions of the problems of such a calorimeter.

The development of this calorimeter should be viewed as involving two major efforts. The necessary first effort was to overcome the physical problems in making the calorimeter an effective and accurate instrument for measuring a temperature rise at a point in water. In this respect, investigations and experience have shown that there are really no major problems with the calorimeter. It is an efficient instrument. It is relatively easy to construct, can be put into operation quickly, and is much easier to control and to operate than solid-bodied absorbed dose calorimeters requiring vacuum systems. The ease of control was made possible because advantage was taken of the mobility of water to quickly bring the calorimeter to a uniform operating temperature, but more important is that use is made of a unique and simple method that essentially instantly eliminates relatively large temperature drifts by merely changing a potential across immersed electrodes [2]. The second major effort is to determine the existence of and corrections for heat defects (negative and positive) in distilled water. This will be a relatively long investigation, both experimentally and theoretically, using different irradiation beams and dose rates. The present paper describes measurements only for cobalt-60 irradiation.

\section{Measurement Theory}

The measurement theory for the determination of absorbed dose in water is described in this section. Effects of conductive temperature changes at the position of measurement were determined by application of a simple and well-known graphical method of calculating changes in a temperature profile. The temperature profile will be undisturbed by buoyant forces if they are not sufficiently large to set convection in motion.

\subsection{Measurement}

Advantage was taken of the low thermal diffusivity of water (that retards a temperature change at a point of measurement) and of the imperviousness of polyethylene film (that electrically insulates the sensors and their leads). Two bead thermistors placed close together were sandwiched between polyethylene films and immersed in distilled water. The thermistors formed opposite arms of a Wheatstone bridge circuit to double the sensitivity compared to a one-thermistor bridge.

It can be shown that (for small temperature changes and for negligible heat defects, lead resistances, and negligible electrical power changes in the thermistors) the absorbed dose determined with the two-thermistor bridge is:

$$
D=(1 / 2)(\Delta R / R)\left(\overline{\mathrm{S}}^{-1}\right)(c)
$$

where $D \quad$ is the absorbed dose,

$(1 / 2)$ is the result of using two thermistors to measure a temperature,

$\Delta R / R$ is the fractional change in the Wheatstone bridge balancing resistor,

$\bar{S} \quad$ is the mean fractional change in resistance of the thermistors per unit temperature rise, and

c is the specific heat capacity of water.

If $c$ is in $\mathrm{J} /(\mathrm{g} \cdot \mathrm{K}), D$ is in $k G y$. The product $(1 / 2)(\Delta R / R)\left(\bar{S}^{-1}\right)$ is the temperature rise. The sensitivity, $\bar{S}$, was determined to an accuracy of about 0.1 percent and was stable over long periods of time. A table of accurate values of $c$ versus temperature is given in Ref. [7]. The values are listed to five figures and vary by only one part in 10,000 per degree Kelvin.

\subsection{Conduction}

Exact theoretical calculations of three dimensional heat flow present a time-consuming and formidable challenge, which may even then be of little or no value in applying calculated temperature corrections to measurements. A theory would be based on an assumption of detailed knowledge of the absorbed dose distribution and that the background drift rates remain zero, are constant, or follow an assumed behavior when in practice they are always subject to unpredictable or difficult-to- 
predict changes. These drifts could be caused by external or internal sources, such as the rapidly changing temperature distributions caused by successive runs with collimated beams of low energy electrons. These changes affect the observed temperature rise and the curvatures of the initial and final drifts. However, calculations have value when they indicate the magnitude of a correction, which is useful for the experimenter to determine the approaching limit of accuracy of measurements. For example, theoretical calculations are of value when they indicate an approximate upper bound to the duration of an irradiation ron in which the heat conduction corrections can still be considered small or negligible compared to the overall uncertainty of an experiment. As the background instabilities become a significant fraction of the calculated corrections, the corrections would be applied with increasing uncertainty and eventually would become meaningless. It is the drift rates and instabilities that must be kept small and under control in order to extend the same quality of measurements to lower dose rates and longer irradiation times.

Absorbed dose measurements in water were made with cobalt- 60 beams shaped with square collimators to produce: (1) a broad beam that irradiated the entire calorimeter; and (2) a smaller beam, that had also been used previously to irradiate an absorbed dose graphite calorimeter [8], the measurements being converted to absorbed dose in water [9]. In the former, heat flow was essentially along the beam axis, whereas in the latter heat flow was predominately radial.

Simple calculations of linear heat flow that produces temperature changes at a point of measurement were made by use of an elegant and well-known graphical method $^{3}$ (illustrated below) that can be made to converge to a theoretical solution. The calculations showed that for an instantaneous pulse of a broad and parallel beam of cobalt- 60 gamma radiation, the temperature rise at a 5 -cm depth in water would decrease by only 0.02 percent of the initial rise in $4 \mathrm{~min}$. This small temperature change results from a slowly changing axial temperature profile that causes essentially the same amount of heat to enter as to leave the point of measurement. Although the collimated beam caused much larger temperature changes as a result of radial heat flow, the calculated changes (assuming zero background drift) were also negligible for irradiations lasting several minutes.

Figure 1 illustrates the numerical method applied to radial heat flow along lines through the beam axis and

\footnotetext{
3The Schmidt method [10] is the best known, although a precursor of this method is described by Binder [11]. The method is further described in numerous publications and books on heat conduction, such as Refs. [12-16]. Reference [14] includes the procedures in applying the method to cylindrical and spherical heat now.
}

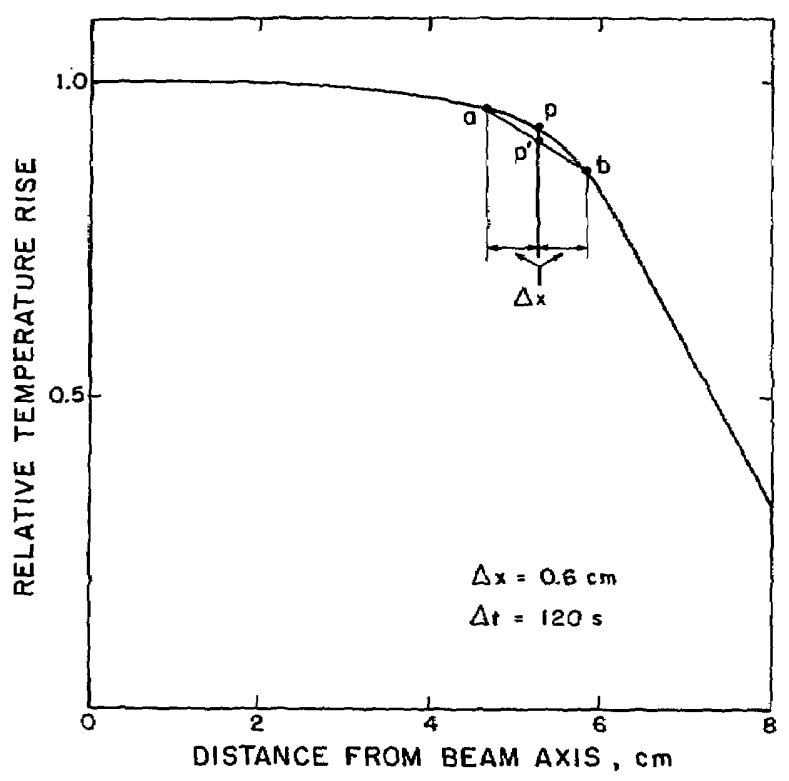

FIGURE 1. Ilustration in applying the Schmidt numerical method to calculate an approximate temperature change in water at a point off the beam axis. The cobalt- 60 beam passed through a square collimator. Conductive heat transfer was primarily radial.

perpendicular to the four sides of the square ${ }^{4}$ of the smaller collimated beam. The curve was determined from densitometer measurements of film exposed under $5 \mathrm{~g} / \mathrm{cm}^{2}$ of polystyrene positioned perpendicular to the beam axis at $1 \mathrm{~m}$ from the source. Densitometer measurements through $p$ and perpendicular to the above described heat flow (parallel to the side of the square beam) showed comparatively little variation in the region of $p$. Therefore, the component of heat flow along that direction could be neglected.

Assume that a beam pulse produced the relative temperature profile shown. It is desired to know the approximate percent decrease in temperature rise from $p$ to $p^{\prime}$ after $120 \mathrm{~s}, \Delta t$. The increments are related by the equation:

$$
(\Delta x)^{2} /(2 \alpha \cdot \Delta t)=1
$$

where is the thermal diffusivity $\left(0.00144 \mathrm{~cm}^{2} / \mathrm{g}\right)$ of water (the thermal conductivity divided by the product of density and specific heat capacityl. Solving the equation gives $\Delta x=0.6 \mathrm{~cm}$. The point of intersection of line $\overline{\mathrm{ab}}$ with the vertical line through $p$ gives the desired point $p^{\prime}$ which is 2 percent lower than point $p$ (calculations

The heat flow pattern away from the irradiated region was much more complicated than the simple linear directional flow described here. Nevertheless, the described direction of heat flow is a good approximation considering the relatively large beam size, and this greatly simplifies the calculations that will be accurate enough for their intended purpose in determining an approximate heat loss correction for a run of given duration. 
can be carried out to any degree of accuracy by testing results with decreasing values of $\Delta x$ ). The calculations can be performed simply and rapidly with a programmed calculator. This was done to determine the change in the profile. The results showed that it would require $23 \mathrm{~min}$, after applying the single-pulsed squareshaped beam, for the temperature rise of the thermistor on the axis to drop by 1 percent, and it would drop only 0.04 percent and 0.24 percent at the end of 3 and 10 min, respectively.

Another illustrative example is shown in figure 2 for the case of a broad beam pulse of $11 \mathrm{MeV}$ electrons on water. At the end of $1 \mathrm{~min}$ the temperature rise $Q$ would drop to $Q^{\prime}$, a decrease of 0.8 percent. Temperature

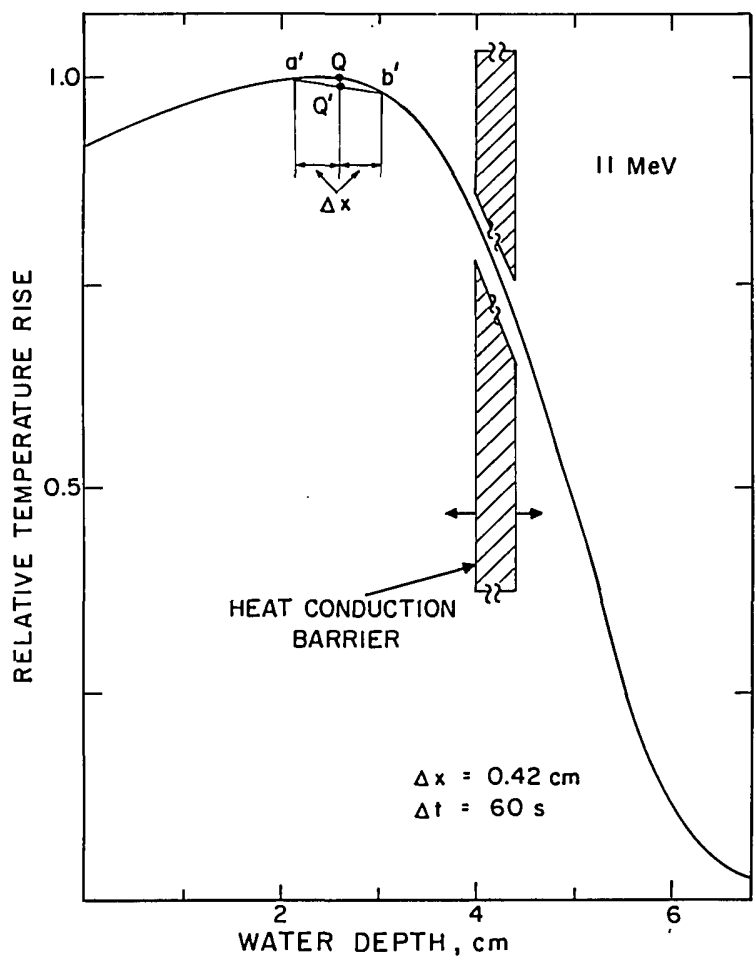

Figure 2. Illustrative sample in calculating the magnitude of a change in temperature at a point on the axis in water irradiated with a broad beam pulse of low energy electrons. Conductive heat transfer is primarily axial and can be decreased by a heat conduction barrier.

changes in long runs would be significantly affected by the steep drop in temperature beyond the peak. (A suitable heat conduction barrier, suitably positioned, in that region would decrease the effect; also, an irradiated nonwater material can act as an excess heat source-ex= plained later.)

The low thermal diffusivity of water results in small theoretically calculated temperature corrections even at positions of large changes in the temperature gradients. Essentially negligible corrections would then result from measurements made immediately after a beam pulse or short runs of constant irradiation.

As will be seen, the calorimeter to be described was sensitive and stable. These features, combined with the large absorbed dose rates which can be delivered with medical therapy beams, are such that only about a minute or two of irradiation time would be needed. They would make the heat loss corrections small or negligible. Even these would tend to be corrected by extrapolating the final temperature drifts.

\subsection{Convection}

Perhaps a faulty belief of the omnipresence of convection in water containing buoyant forces was one of several reasons why the idea of the water calorimeter, if previously conceived by others, was dismissed as infeasible. This concern led to the construction of a calorimeter for measuring absorbed dose in a gelatin medium [17]. Although the present investigator was also initially concerned about convection, the calorimeter was still thought to be feasible if a series of closely spaced convection barriers was used above and below the plane defining the measurement point [1]. An initial design unnecessarily incorporated such a complicated construction. However, it was then learned that it had been wellknown that buoyant forces can exist but the liquid will remain motionless until the Rayleigh number of about 1000 is exceeded [18] (reference [19] is an excellent article on convection). It would be instructive to give a brief description of the theory, followed by an example.

Consider the region before the peak of a temperature profile produced by an irradiation beam directed vertically downward. The temperature of the water in this region will increase with depth. This will cause a buoyant force that would be opposed by the viscous force of the fluid. The Rayleigh number is the product of the Grashof number $\left(G_{r}\right)$ that is a measure of the relative importance of the buoyant and viscous forces and the Prandtl number $\left(P_{r}\right)$ that is a measure of the ratio of the molecular diffusivity of momentum to the molecular diffusivity of energy:

$$
\begin{aligned}
G_{r} & =g \Phi Q^{2} \Delta T d^{3} / \eta^{2}, \\
\text { and } P_{r} & =\eta C_{p} / k,
\end{aligned}
$$

where $g$ is the gravitational force per unit mass,

$\Phi$ is the volumetric expansion coefficient,

$\varrho$ is the density,

$\Delta T$ is the temperature difference between two horizontal planes,

$d$ is the distance separating the planes,

$\eta$ is the viscocity, 
$C_{p}$ is the specific heat at constant pressure, and

$k$ is the thermal conductivity.

Assume that two horizontal convection barriers (consisting of films) are immersed in water and that the lower barrier is $1 \mathrm{mK}$ higher in temperature, which is roughly an upper limit that would be encountered in medical therapy beams. A calculation shows that the Rayleigh number is 1000 when the separation $(d)$ is $4 \mathrm{~cm}$. Therefore, convection barriers (if needed) would consist only of a few and would be widely separated.

Measurements (described later) indicated no evidence of convection even in the absence of the barriers. Initial concerns about convection restricted the design of the calorimeter to vertically downward directed beams, but these calculations, in conjunction with experimental measurements described below, appear to also allow measurements in horizontally directed beams.

\section{The Calorimeter}

Figure 3 is a drawing that shows some features of the calorimeter. Two $0.25-\mathrm{mm}$ diameter bead thermistors

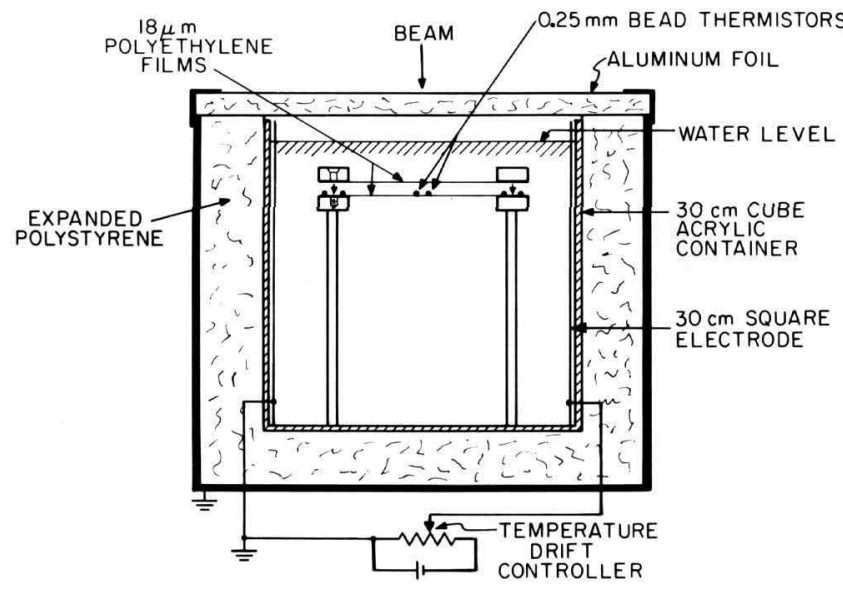

FigURE 3. Essential features of the absorbed dose water calorimeter.

(separated by $2.5 \mathrm{~mm}$ ) were sandwiched between two 18 $\mu \mathrm{m}$ thick polyethylene films immersed at a $5 \mathrm{~cm}$ depth in water. The films were tightly stretched and clamped between two polystyrene rings (152 $\mathrm{mm}$ i.d., $214 \mathrm{~mm}$ o.d., and $23 \mathrm{~mm}$ total thickness). The rings were fastened with screws to three acrylic rods (polymethylmethacrylate) secured to the bottom of a $30-\mathrm{cm}$ cube water container constructed of the same acrylic material. Two drift control electrodes, $30 \mathrm{~cm}$ square and $0.6 \mathrm{~mm}$ thick stainless steel, were secured against two opposite vertical walls inside the container. One electrode was connected to ground in order to ground the partically conductive once-distilled water. The drift control potential supply consisted of several $671 / 2 \mathrm{~V}$ dry-cell batteries placed in parallel, and these were connected across a 10-turn 50 $\mathrm{k} \Omega$ helipot connected to the electrodes. A digital voltmeter and ammeter displayed the potential and current through the water. These values were recorded and used to calculate the power dissipation in the water, its resistance, and its electrical resistivity throughout a series of measurements. The depth of the water in the container was $26 \mathrm{~cm}$. The calculated electrical capacitance between the electrodes of the filled container was about $200 \mathrm{pF}$.

An electrically grounded magnetic shield, consisting of $1.3 \mathrm{~mm}$ thick plates (not shown), surrounded the outer walls and the bottom of the water container. The container also was surrounded by a thermal shield of expanded polystyrene which, in turn, was surrounded by an electrically grounded shield of aluminum. An easily removable lid was snap-secured to the exterior duraluminum container. The lid thickness was $4 \mathrm{mg} / \mathrm{cm}^{2}$ of aluminum and $75 \mathrm{mg} / \mathrm{cm}^{2}$ of expanded polystyrene. The external dimensions of the outer container were $45 \times 45 \times 40 \mathrm{~cm}$ high, and the mass (without water) was $31 \mathrm{~kg}$.

Figure 4 is a top view photograph that shows additional interior details. The signal leads from the thermistors passed through Teflon spaghetti and a connector shown on the top of the rings. Silicone rubber and a rubber sleeve waterproofed the connector. (Additional details that describe the emergence of the leads are given in a previous report [1]). The connector and the three

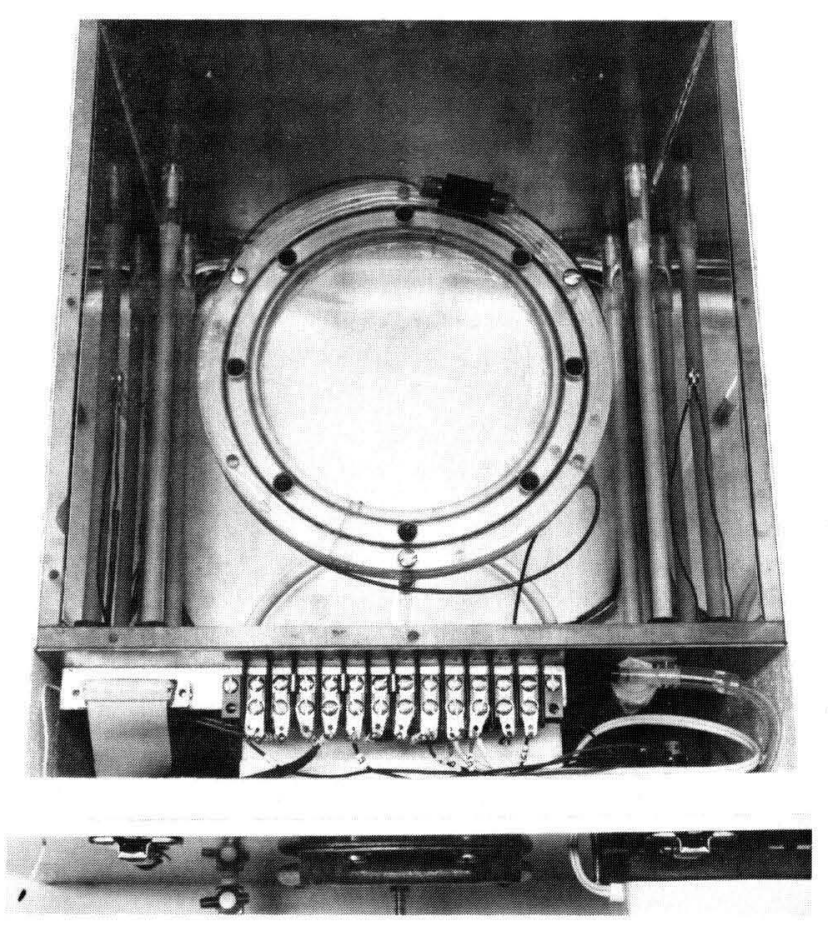

FigurE 4. Top view photograph showing calorimeter internal details. 
securing screws permitted easy placement or removal of the detector assembly. The left and right sides show the stainless steel drift control electrodes, each showing reflections of two horizontally mounted immersion heaters (400 W total power for the four heaters) enclosed in quartz sheaths. Not visible between two of the heaters was a horizontally positioned commercial temperature sensor in a stainless steel sheath. A perforated plastic tube was positioned along the bottom horizontal interior edges of the tank for the purpose of agitating the water with air, oxygen, or nitrogen at a flow rate near 1.5 $\mathrm{L} / \mathrm{min}$. The gas was made to flow directly upward near the four vertical corners of the tank to effectively prevent gas bubbles from migrating to the bottom surface of the lower film. The lower part of the photograph shows the connecting points for wires between the two enclosures of the calorimeter. The wires, immersion heaters, perforated tube, and the temperature sensor all entered the water tank through seals below the water surface for easy removal of the lid. The lower left-hand corner of the photograph shows another temperature sensor for measuring the temperature outside the exterior box. Both probes were connected to an instrument that displayed temperature with a resolution of $0.01 \mathrm{~K}$.

Figure 5 shows the external features. The lid is shown snap-secured to complete the thermal and main electrostatic shielding. An aquarium pump, shown mounted

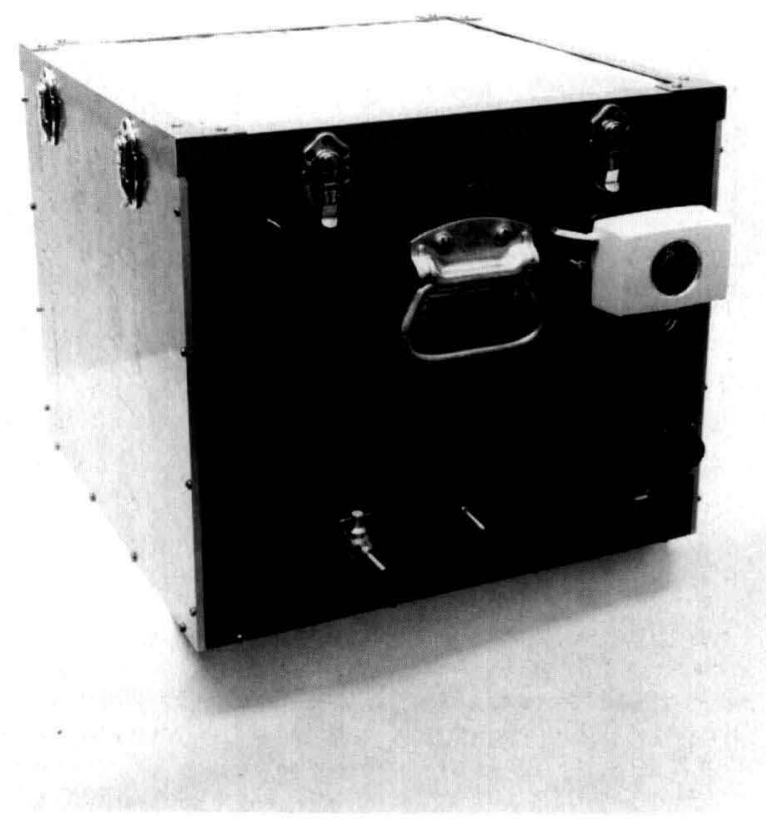

Figure 5. Photograph showing calorimeter external details. adjacent to the handle, was occasionally used to agitate the water. Agitation with oxygen or high-purity nitrogen was accomplished by connecting those supplies with the pump outlet connecting tube. $A$ valve (shown at the lower left) was connected to the water tank with a plastic tube at a position near the bottom of the tank. A tube connection from the valve outlet to an external column of water would permit micrometer measurements down to the water surface which would provide a convenient way of accurately measuring changes in the depth of the immersed thermistors, after water is added to or removed from the column.

A tube fitting (to the right of the valve) was connected to the same nitrogen or oxygen supply used to agitate the water, and after agitation a small amount of the gas continued to flow between the two containers to prevent air from diffusing back onto the water surface. Signal lead and control cables (16 m long) were attached to the connectors shown at the lower right.

If necessary, the temperature around the calorimeter could be accurately controlled by means of a structure placed over the calorimeter. This four-sided acrylic structure contained a temperature sensor, heater, and fan mounted on an inside wall. The lid of this structure was expanded polystyrene with a polyethylene film covering the beam entrance window.

\section{The Detector}

The amount of non-water materials near the thermistors must be kept at a minimum. Those materials act as generators of excess heat that must be sufficiently dissipated to cause negligible effects, or the effects must be calculated so that corrections can be made. The 25 $\mu \mathrm{m}$ diameter thermistor leads $(90$ percent platinum-10 percent iridium, and nearly $1 \mathrm{~cm}$ long) were soldered to $80 \mu \mathrm{m}$ diameter copper wires. The excess length of each soldered junction was cut away with a surgical blade. Each junction was then attached to the lower film with a minimal amount of silicone rubber. Each pair of junction points was separated about $15 \mathrm{~mm}$, and the copper wires were separated by at least that amount. This separation permitted more rapid dissipation of excess heat from the wires compared to wires placed close together. The length of the copper wires was made to be about $14 \mathrm{~cm}$ before being allowed to exit from the inside diameter of the rings. Just prior to securing the rings together, several scattered spots of silicone rubber were placed on the lower film, at least $2 \mathrm{~cm}$ away from the thermistors and wires. The spots were compressed immediately after securing the rings, adding further assurance of closer film contact. Close examination at the thermistors revealed bulging on both sides of the films which were presumably in good thermal contact 
with the thermistors. There were observed non-uniform contacts of the films with the wires. Contact between the remainder of the films looked good. All thermal contacts were undoubtedly improved by water pressure on both sides of the films. 5

The assembled detector was examined under a microscope to view the films for tiny weak spots which were sealed by application of tiny amounts of silicone rubber (care was taken that obvious weak spots were not in the immediate vicinity of the thermistors).

The thermal effects of the films, beads, and bare Pt-Ir leads were calculated from theoretical solutions [20]. The effects of the films on the thermistors were calculated by using a slightly modified form of the theoretical solution (eq (10), p. 76 in [20]). Figure 6 shows the calculated excess thermistor temperature rise caused by the films, in percent, as a function of time after a 3-min irradiation run. The correction is small and it decreases as the duration of the run increases. The correction at the instant of beam turn off after a one-, two-, or three-minute run is $0.31,0.22$, and 0.18 percent respectively. The small variable corrections can readily be applied to the observed calorimeter signals, after

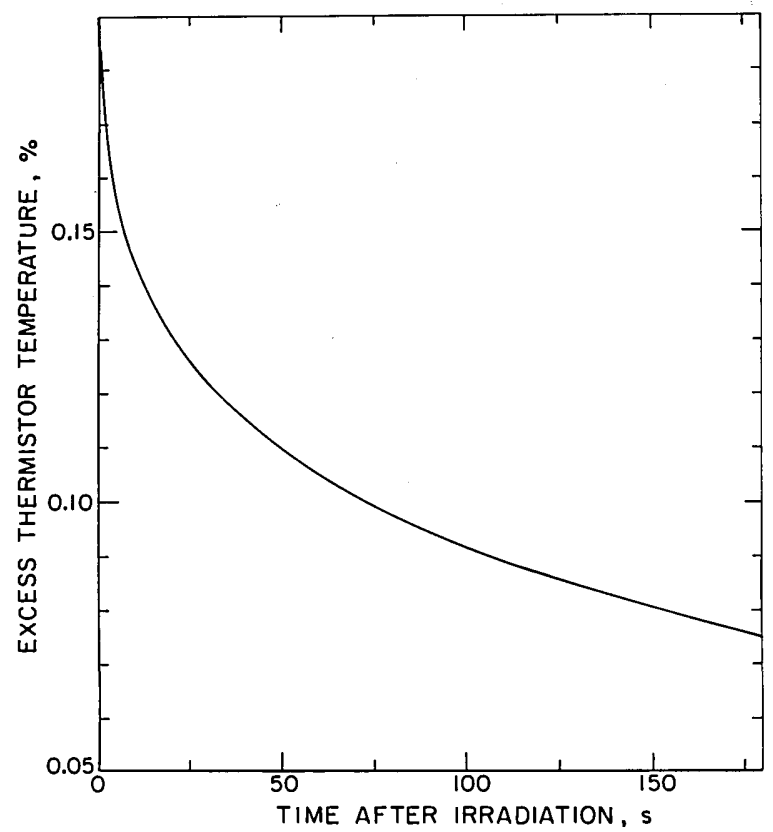

Figure 6. Excess thermistor temperature rise caused by the two immersed $18 \mu \mathrm{m}$ polyethylene films irradiated for three minutes.

\footnotetext{
${ }^{5}$ Calculations showed that even if the plane between the films (at a 5-cm depth of water) acted as an impervious conductive barrier to heat flow after a pulse from a broad parallel beam of cobalt-60 radiation, but the thermistors represented the average temperature at the water boundaries, then such a barrier would cause an error in measurement of only 0.03 percent at the end of 3 minutes.
}

beam turn off. The corrections are taken to be accurate considering the well defined geometry and known thickness of the films. The effects of the beads and wires were calculated by considering them as isolated but continuous point and line sources of heat in water, the theoretical solutions being formulas (2) and (5), respectively, on p. 261 in reference [20]. Their effects were negligible even though the geometry assumed here was not realistic in practice. Results of the calculations showed that their separate excess temperature effects would essentially disappear, within 0.01 percent, a few seconds after beam turn off. The fast disappearance of excess heat from the beads and wires is a result of spherical and cylindrical flow of heat, respectively, away from them; whereas it is slower from the films because of the linear flow of heat.

Polyethylene appears to be a good choice for the sandwiching films. In regard to generated excess heat, this material produces a smaller effect for a given thickness than, for example, Mylar (polyethylene terephthalate) by approximately a factor of 1.7-the ratio of their specific heat capacities, which is the dominant factor causing that effect. In regard to the water absorption characteristics of these two materials, polyethylene is lower by at least a factor of 20 (according to data listed in reference [21]). Early tests showed that polyethylene films provided high electrical insulation from water. In one test two $30 \mu \mathrm{m}$ films sandwiched two $15 \mathrm{~cm}$ diameter aluminized plastic foils, each $6 \mu \mathrm{m}$ thick. The aluminized layers (electrically connected) were against the $30 \mu \mathrm{m}$ sandwiching films. This unit was kept immersed in water for two weeks while daily electrical resistance measurements were made between the aluminum and water. The geometry, therefore, was such that leakage resistance anywhere through the films would be included in the measurements. On the first day, the resistance was $5 \times 10^{12} \Omega$. On the other days, the measurements varied from 1.3 to $4.0 \times 10^{11} \Omega$ which were still sufficiently high resistance values. ${ }^{6}$ (The electrical resistance between two points in the water was negligible in comparison with the resistance through the films). The sandwiching films were not previously inspected under a microscope for weak points (only visual observations were made). Polyethylene films have a desirable property in that they can be slightly stretched

\footnotetext{
6Perhaps the best test for intolerable leakage resistances can be judged by observation of the recorded bridge output signal, using an amplifier gain normally used for measurements. Small variations in leakage resistance would likely be present, and this could result in large and erratic noise particularly when measuring small output signals. This was never observed with the detector described in this paper (the detector was immersed only during the course of daily measurements). If internal difficulties from this source occur, the detector can easily be removed for repair or replaced. This simple procedure is in striking contrast to painstakingly rebuilding a calorimeter constructed of sealed nested bodies made of solid material.
} 
without apparent damage. This eliminates wrinkles when the films are stretched around the rings with elastic tape during detector fabrication and assembly.

The detector polystyrene mounting rings had a specific heat capacity nearly one-third that of water. The absorbed dose rate in the two materials is approximately the same. Therefore, a pulse of broad beam irradiation will cause an instantaneous rise in temperature about three times higher in the rings than in the surrounding water. Heat produced in them, during typical 3-min irradiation runs, caused a negligible effect on the centrally located thermistors. An upper limit to the effect was calculated by using theoretical results listed in table J.1 of reference [12]. The table would apply to the rings being infinite in extent in the vertical direction and the cylinder receiving a sudden change in temperature which remains constant with time. The result showed that 20 min would be required for thermal conduction from that cylinder $(152 \mathrm{~mm}$ i.d.) to raise the temperature of the thermistors by 0.1 percent of its initial temperature rise. In reality, the total thickness of the rings was small, the temperature of the rings decreased rapidly from loss of heat (because of the small specific heat capacity), and the heat conducted from the inside lateral ring surface was diffuse in direction. Consequently, many irradiation runs had to be made before the thermistors significantly sensed the heat conduction, and whenever they did the effect helped to control and speed the measurements, as will be explained later.

\section{The Wheatstone Bridge}

Figure 7 is a drawing of the simplified Wheatstone bridge circuit that was used for determining both the fractional resistance change $(\Delta R / R)$ in the balancing resistor $(R)$ and the fractional change in thermistor resistance per degree temperature rise $(S)$ of each thermistor, C and J. A selector switch (not shown) could replace each thermistor with an external resistor of equal value (the power through the replaced thermistor remaining constant by means of an auxiliary variable power supply). Also provided were means for independently varying the power through each thermistor. ${ }^{\text {? }}$

Each thermistor had a nominal resistance value of 3 $k \Omega$ at the water bath operating temperature of about 23 ${ }^{\circ} \mathrm{C}$. The bridge power supply was two $1.35 \mathrm{~V}$ mercury cells that could be switched in series or in parallel. These were in series with a variable resistor, $R_{1}$, that consisted

7The circuit features were the same as for the absorbed dose graphite calorimeter described in reference [8]. These permitted a rapid means for making important tests to determine the consistency of the measurements in the $\mathrm{C}$, J, and $\mathrm{C}+\mathrm{J}$ modes that are described later.

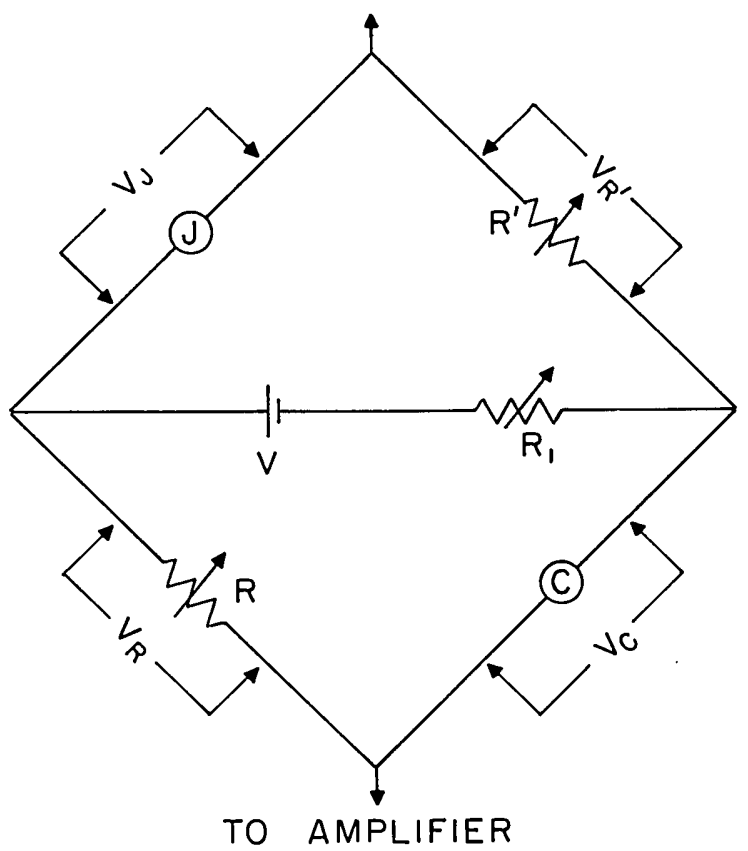

Figure 7. Wheatstone bridge circuit used for determining the absorbed dose and the absolute sensitivity of the thermistors.

of a 10-turn helipot and a selector switch that placed additional resistors in series. These arrangements permitted a large range of power dissipations in the thermistors to study their effects on the measurements of absorbed dose, thermistor sensitivities, and possible water convection in the immediate vicinity of the thermistors.

A selector switch permitted measurements of the potentials $V_{C}, V_{\mathrm{J}}, V_{\mathrm{R}}$, and $V_{\mathrm{R}^{\prime}}$, between pairs of points along each bridge arm. Prior to a series of measurements, the resistor $R^{\prime}$ was adjusted until $V_{\mathrm{J}}$ was essentially equal to $V_{R^{\prime}}$. Then resistor $R$ was adjusted to bridge balance. This made the $J$ thermistor resistance value, $r_{\mathrm{J}}$, essentially equal to the resistance value of $R^{\prime}$, and the $C$ thermistor resistance value, $r_{C}$, essentially equal to the balancing resistance value of $R$ (external lead resistances had a small effect). This bridge condition resulted in minimal changes in thermistor powers during the course of the runs. The four measured potentials were also used to determine the sensitivity $(S)$ of the thermistors.

The dc output of the bridge was fed into a $16 \mathrm{~m}$ double-shielded signal cable connected to a nanovolt null detector that consisted of a chopper, ac amplifier, and demodulator system followed by a dc amplifier. The signal cable consisted of nine pairs of $640 \mu \mathrm{m}$ diameter copper wires, each pair separately shielded. A change in room temperature will change the resistance of the signal leads and that will cause a change in the bridge output. This effect was minimized in the following manner: the two wires within a pair would presumably be closer to 
the same temperature than two wires from separate pairs. Therefore, leads from a pair were positioned in adjacent arms of the bridge that would essentially remain in balance for equal resistance (temperature) changes in the leads. In a similar manner, to further decrease the effect, separate leads from two other pairs were placed in parallel to the first pair to decrease the conductive path arm resistance to $0.3 \Omega$.

Optimum measurement conditions required that the resistance values of the components in the variable resistance arms, $R$ and $R^{\prime}$, depended on whether the bridge was to be used for measuring the sensitivities of the thermistors (when the water bath temperature was made to vary from $9-34{ }^{\circ} \mathrm{C}$ ) or absorbed dose (when the water bath temperature was essentially constant). For the former, $R$ and $R^{\prime}$ were decade resistors which provided dial resistance values of $10(0.1+1+10+100+$ $1000) \Omega$ and $10(1+10+100+1000+10,000) \Omega$, respectively. Each had a resistance accuracy of 0.05 percent. Their terminals were shielded by grounded metal enclosures surrounded by thermal insulation. For absorbed dose measurements (when very small signals at a high amplifier gain had to be measured), $R$ was shunted with a $1.5 \mathrm{k} \Omega$ resistor and the combination was in series with a $1.55 \mathrm{k} \Omega$ resistance combination, while $R^{\prime}$ was shunted with a $2.5 \mathrm{k} \Omega$ resistor and this combination was in series with a $0.8 \mathrm{k} \Omega$ resistance combination. These resistance arrangements attenuated possible effects of contact resistance changes in the dials and also permitted desirably small recorder-pen deflections with changes in the smallest dial steps.

Effects of thermal electromotive forces (emfs) were decreased mainly by providing thermal insulation around the bridge circuit enclosure. The abovementioned resistors were wire-wound (non-inductively), and it was necessary to enclose them within that insulation. All components were soldered with an ordinary solder alloy of 60 percent tin, 40 percent lead. An emf stability test was made by connecting a thermally insulated mini-box (at the calorimeter end of the signal cable) containing two fixed wire-wound resistors that replaced the thermistors. A prolonged test indicated entirely satisfactory stability; and although changes in temperature drift were observed at times, they were too slow and predictable to impair the precision of measurements. This setup provides an additional test in determining if problems (if they do occur) are caused within or exterior to the calorimeter outer container.

\section{Thermistor Sensitivity Measurements}

The thermistor resistance value $(r)$ at a given absolute temperature $(T)$ is given by the well-known empirical expression:

$$
r=r_{0} e^{\beta\left(1 / T-1 / T_{0}\right)}
$$

where $r_{0}$ is the resistance at temperature $T_{0}$ and $\beta$ is the "material constant."8

The sensitivity of a thermistor $(S)$ is defined as $(1 / r)(d r / d T)$, which gives

$$
S=-\beta / T^{2} .
$$

The sensitivity is nominally 4 percent per degree and varies by seven parts per thousand per degree at room temperature. Equation (3) can be reduced to linear form:

$$
y=\beta x+\theta,
$$

where $y=\ln r, x=1 / \mathrm{T}$, and $\theta=\ln r_{\mathrm{o}}-\beta / T_{0}$, a constant.

The values $\beta_{C}$ and $\beta_{J}$ for each thermistor were derived from resistance measurements $\left(r_{\mathrm{C}}\right.$ and $\left.r_{\mathrm{J}}\right)$ determined within the beads as a function of temperature within the beads. Least-squares fits of the data were applied to eq (5).

Figure 8 shows smooth plots of the $\mathrm{C}$ and $\mathrm{J}$ thermistor resistances as a function of their temperatures from 9-34 ${ }^{\circ} \mathrm{C}$. Table 1 lists the results of the analysis. Column 1 shows the different months in which the measurements were made. Column 2 shows the chosen temperature ranges, and column 3 shows the number of data points in those ranges. Columns 4 and 5 list the calculated values of $\beta_{C}$ and $\beta_{J}$ for the $C$ and $J$ thermistors, respectively. In all cases, the least-squares fits resulted in variations in the coefficient of correlation that differed from unity by less than one part in 10,000 . A value of unity would represent a perfect fit for the data.

An examination of the data indicates that sufficiently accurate and repeatable results would be obtained from about ten data points over a temperature span of approximately 6 degrees above and 6 degrees below the calorimeter operating temperature. The values of $\beta_{C}$ and $\beta_{\mathrm{J}}$ differed by 0.4 percent. A mean value $\bar{\beta}$, of $3202 \mathrm{~K} \pm$ 0.1 percent was used for the final result. Careful measurements showed that there was no detectable evidence of variation in $\beta_{\mathrm{C}}$ or $\beta_{\mathrm{J}}$ at eight different values of thermistor power dissipation from $6-200 \mu \mathrm{W}$.

The water bath temperature, $T_{w}$, was measured with a separate sensor probe connected to a circuit that displayed temperature with a resolution of $1 \mathrm{mK}$. The probe

\footnotetext{
${ }^{8}$ Although $\beta$ increases slightly with increasing temperature $[22,23]$, it may be considered constant over temperature spans of approximately $40 \mathrm{~K}$, depending on the thermistor material and the absolute temperature of the center of the span [24]. Furthermore, slight effects of variations in $\beta$ will be decreased by analyzing data within equal temperature spans around the calorimeter operating temperature, near $23^{\circ} \mathrm{C}$.
} 
was a calibrated commercial quartz thermometer. Tests showed that movement of the probe to different positions in the water (after agitation) indicated no significant differences in observed temperature. Another test showed that the power dissipation in the probe raised its temperature by $4 \mathrm{mK}$, which was subtracted from the displayed values. The Wheatstone bridge electrical power

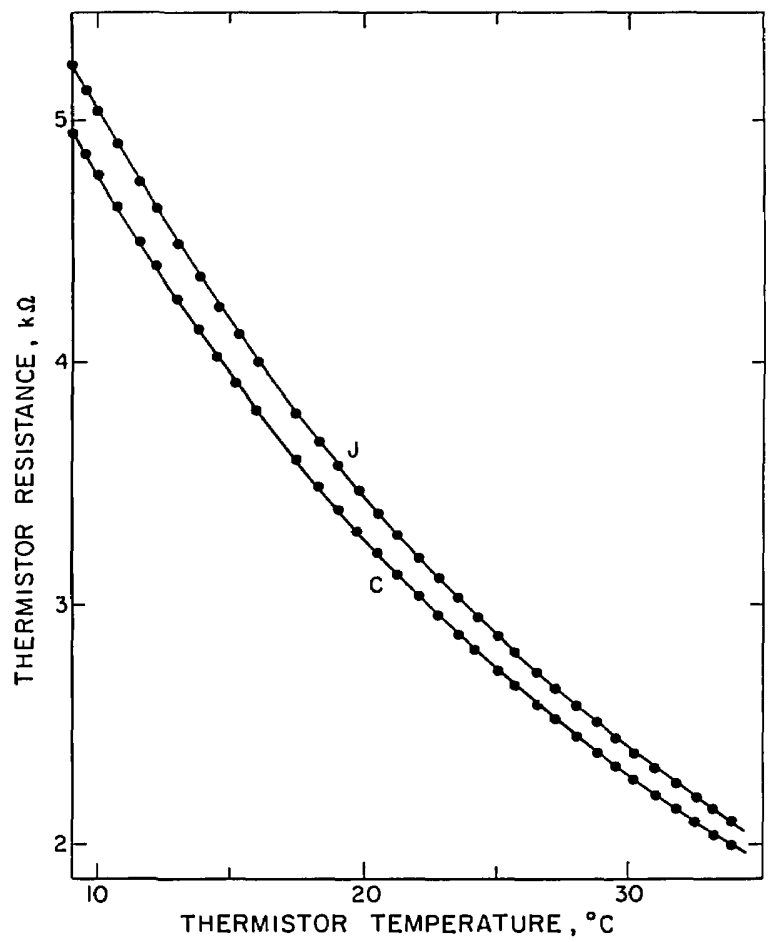

FIGURE 8. Plots of measured thermistor resistances versus temperature.

TABLE 1. Measured values of $\beta$.

\begin{tabular}{c|c|c|c|c}
\hline \hline Date & $\begin{array}{c}\text { Temperature } \\
\text { range } \\
(1980)\end{array}$ & $\begin{array}{c}\text { Date } \\
\text { points }\end{array}$ & $\begin{array}{c}\beta_{\mathrm{C}} \\
(\mathrm{K})\end{array}$ & $\begin{array}{c}\beta_{\mathrm{J}} \\
(\mathrm{K})\end{array}$ \\
\hline & $13-34$ & 28 & 3193.3 & 3207.3 \\
March & $16-31$ & 20 & 3195.0 & 3209.1 \\
$"$ & $19-28$ & 13 & 3194.4 & 3205.2 \\
& $20-26$ & 9 & 3196.1 & 3204.7 \\
\hline Sept. & $14-33$ & 21 & 3189.5 & 3208.5 \\
$"$ & $16-29$ & 14 & 3183.4 & 3210.4 \\
$"$ & $19-26$ & 8 & 3195.8 & 3206.7 \\
& $20-25$ & 6 & 3202.2 & 3201.3 \\
\hline Nov. & & & 3199.7 & 3202.2 \\
$"$ & $12-33$ & 8 & 3192.9 & 3204.2 \\
$"$ & $16-30$ & 6 & 3198.7 & 3212.1 \\
& $19-27$ & 4 & 3207.1 & 3221.7 \\
\hline & & & 3201.5 & 3212.7 \\
\hline
\end{tabular}

dissipations in the thermistors, $\boldsymbol{P}_{\mathrm{C}}$ and $\boldsymbol{P}_{\mathrm{J}}$, caused them to rise, $\Delta T_{\mathrm{C}}$ and $\Delta T_{\mathrm{J}}$, above the water temperature, $T_{w}$. The mean values of the differential temperatures, $\overrightarrow{\Delta T}$, were determined experimentally (shown below) and were later added ( $24 \mathrm{mK}$ for most of the measurements) to the values of $T_{w}$ displayed on a meter. A calculation showed that a systematic error as large as $100 \mathrm{mK}$ throughout the temperature range would have resulted in an error in $\beta_{\mathrm{C}}$ or $\beta_{\mathrm{J}}$ of only 0.07 percent.

When the Wheatstone bridge was balanced, the values $R, R^{\prime}, V_{\mathrm{C}}, V_{\mathrm{J}}, V_{\mathrm{R}}$, and $V_{\mathrm{R}}$, were recorded and stored in the registers of a programmed calculator. Included in the computer program were the effects of all lead resistances external to the beads, including the effects of the exact locations of the four potential measurements. The computer printouts gave values of $r_{\mathrm{C}}$ and $r_{\mathrm{J}}$ (the electrical resistances within the beads), and $P_{\mathrm{C}}$ and $P_{\mathrm{J}}$ (the electrical powers dissipated within the beads). These results permitted determinations of small temperature corrections, $\overline{\Delta T}$. Then $T=T_{w}+\overline{\Delta T}$, for use in eq (5).

Figure 9 shows normalized plots of the equilibrium thermistor resistances, $r_{\mathrm{C}}$ and $r_{\mathrm{J}}$, as a function of thermistor electrical power dissipations, $P$, in microwatts. The measured values for $r_{\mathrm{J}}$ are not shown. The resistances, $r_{\mathrm{J}}$, were about 5 percent higher than $r_{\mathrm{C}}$, but was normalized to $r_{\mathrm{C}}($ at $P=0$ ) to better show the difference in slopes of the linear fits of the form $r=m P+$ $n$. The small difference in slopes was presumably caused by differences in thermal coupling between the thermistor beads and connecting wires with the surrounding

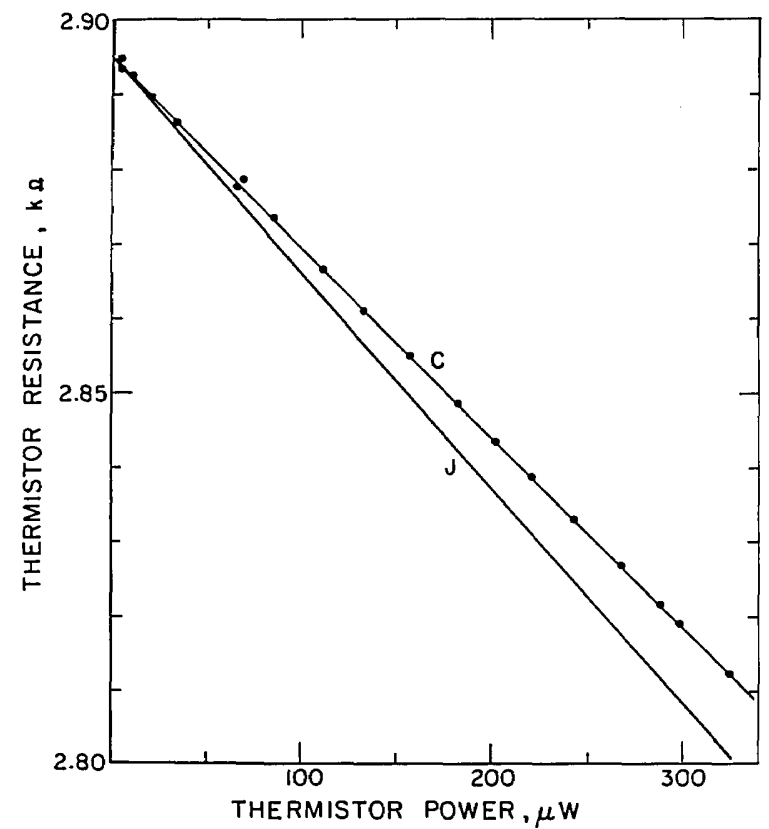

Figure 9. Normalized plots of equilibrium thermistor resistances versus electrical power dissipations. Data points are plotted for $\mathrm{C}$ curve only. 
films and water. The plots were converted to temperature scales by the equation:

$$
\Delta T_{\mathrm{C}, \mathrm{J}}=\frac{m_{\mathrm{C}, \mathrm{J}} P_{\mathrm{C}, \mathrm{J}}}{n_{\mathrm{C}, \mathrm{J}}\left(\beta_{\mathrm{C}_{+} \mathrm{J}}^{\prime} / T_{w}^{2}\right)}=\phi P_{\mathrm{C}, \mathrm{J}},
$$

where $\beta_{C}^{\prime}$, were first approximations of $\beta_{C}$ and $\beta_{J}$ determined from measurements of resistances versus $T_{w}\left(P_{C}\right.$ and $P_{\mathrm{J}}$ were about $5 \mu \mathrm{W}$ so the values of $\Delta T_{\mathrm{C}}$ and $\Delta T_{\mathrm{J}}$ were negligible for these determinations). Plots like figure 9 were made at eight operating bath temperatures from $10-33^{\circ} \mathrm{C}$. The mean value of $\phi$ for the two thermistors was $2.6 \mathrm{mK} / \mu \mathrm{W} \pm 1$ ' percent mean error, and was essentially constant over this temperature range.

Equation (1) can now be put in a more usable form:

$$
D=(1 / 2)(\Delta R / R)(\bar{\beta}-1)\left(T_{w}+\overline{\Delta T}\right)^{2}(c)
$$

where $\overline{\Delta T}=2.6 \bar{P} \mathrm{mK}$, and $\bar{P}$ was the average power, in $\mu \mathrm{W}$, of the two thermistors.

\section{Calorimeter Setup}

The following procedure was followed each morning in preparation for irradiation runs. The calorimeter (fig. 3) was empty of water, the lid was removed, and zero potential was across the drift control electrodes. A horizontal line-of-sight of a telescope (mounted on a distant vertical scale) was used to indicate a $1 \mathrm{~m}$ distance from the cobalt- 60 source. The thermistors were to be placed along this line. A bar was placed across the top of two opposite edges of the 30-cm cube container. A depth micrometer was placed on the bar and a measurement (A $\mathrm{mm}$ ) down to the film was made to a accuracy of about $\pm 0.025 \mathrm{~mm}$. The line-of-sight of the scope was then raised by $\mathrm{A} \mathrm{mm}$. The height of a sturdy motorized platform (on which the calorimeter rested) was adjusted until the line-of-sight coincided with the plane between the micrometer base and bar (this was later checked when the tank was full of watert. This placed the thermistors at the reference distance of $1 \mathrm{~m}$, the same place at which previous measurements were made with the NBS absorbed dose graphite calorimeter.

The next step was to place the plane of the thermistors at a $50 \mathrm{~mm}$ depth in water, with a micrometer reading of (A-50) $\mathrm{mm}$ to the water surface. Water was then allowed to flow into the container, and as it rose air was trapped within the boundaries of the film and lower ring. The trapped air was completely removed with a suction syringe. When electrical contact between the micrometer and water was made, the water flow was stopped. A measurement to the water surface usually differed slightly from the required (A-50) $\mathrm{mm}$ value. This difference was eliminated by adding or withdrawing the required volume of water with a graduated hypodermic syringe. The lid was then snap-secured, and temperature control was ready to begin.

\section{Temperature Drift Control}

When the calorimeter was being constructed, two seals were installed at the bottom of the water tank for the use of cooling coils to aid in the temperature control, if necessary. These were never put into use because the method of controlling temperature drifts described below was found to be adequate.

Initial temperature measurements made with the sensor probes indicated that the water bath was always about $1^{\circ} \mathrm{C}$ cooler than the immediate surroundings. The reason is that on the previous day the storage bottles containing the water were placed at floor level where the temperature was cooler than at the elevated calorimeter. This condition helped to bring the calorimeter under control.

The initially cool water started to cool the container walls and polystyrene rings (the thermal diffusivity and thermal conductivity of the polystyrene were lower than that of water by approximately factors of two and five, respectively). The calorimeter is most stable when the water bath temperature is raised to the environmental temperature. Water agitation was started and the immersion heaters were turned on and then turned off after approximately $4 \mathrm{~min}$ to allow the temperature difference between the water and the ambient (near $23^{\circ} \mathrm{C}$ ) to settle within $0.2^{\circ} \mathrm{C}$ (daily room temperature variations were near $0.2^{\circ} \mathrm{C}$ ). At this point, the average temperature of the rings (the principal structure nearest the sensors) lagged too far behind the water bath temperature, but the agitation continued for about $20-30 \mathrm{~min}$ (a small gas flow within the outer container continued throughout the day). At this point, the lag in ring temperature was desirably small. The agitation was stopped and a period of approximately $10 \mathrm{~min}$ was allowed for the water turbulence to subside. The gain of the amplitier was increased and the drift of the bridge output as indicated by the recorder was observed. The recorder at first always indicated a characteristic upward drift (temperature increasel that gradually peaked and then tnrned into a small (and desirable) cooling drift. The reason for this behavior is that at first the Wheatstone bridge electrical power produced sharp temperature gradients around the thermistors, which gradually approached a steady state, but which were then overcome by conduction of heat to the cool rings. A potential was then applied across the drift control electrodes, and adjusted until the drift was greatly reduced. In this way, a temperature drift was 
quickly brought under control ${ }^{9}$ by increasing or decreasing the electrical heating of the distilled water which was slightly electrically conductive.

After continued agitation $(-30-40 \mathrm{~min})$, the cooling drifts at times were small enough to allow runs with zero potential across the electrodes. ${ }^{10}$ In theory, prolonged agitation followed by a long wait should result in an initial zero drift, but in practice external effects coulả be significant.

On two days (out of approximately 40), there were long and steady initial heating drifts when the potential across the plates was zero, a seemingly uncontrollable situation. However, control was easily restored. The water bath was agitated and raised in temperature about $0.1^{\circ} \mathrm{C}$. This made the rings again lag behind the water temperature, again causing a slight cooling of the thermistors, and thus permitting drift control. This procedure is better than attempting to control the situation by initially starting with too high a power between the electrodes (zero power was used although a small initial power would be satisfactory), and then decreasing the high power to control small heating drifts. In a room well regulated in temperature, drift control is relatively easily achieved when the initial temperature of the water is not greater than room temperature. Excessive initial temperature of the water may result in undesirably large cooling drifts.

Helpful to the understanding of the drifts is the degree to which the rings lag behind the water in temperature. Consider, for example, that the rings and water are initially at a uniform temperature and then the water is suddenly raised in temperature by one degree and water agitation is started. The changes in temperature at the geometric center of the ring cross section (with the rings considered as one piece with dimensions of $23 \times 65 \mathrm{~mm}$ ) were calculated from existing tabulated results derived from theoretical calculations. At 10, 20, 30, and 40 mins, the temperature differences from water would be about $500,180,60$, and 20 millidegrees, respectively.

The effectiveness in controlling drifts depends on the axial and radial absorbed dose profiles. Successive

\footnotetext{
9This is a vital feature that calorimeters must have; otherwise, these instruments are too unwieldly, which discourages their construction and use. In the NBS absorbed dose graphite calorimeter [8] drifts were also quickly brought under control in its four nested bodies. Described in the cited reference is the method of momentary observation of the drift in each body followed by selective temperature adjustments to bring the bodies to a state of temporary equilibrium for a long enough period to complete at least several irradiation runs.

${ }^{10}$ Experience has shown that these conditions were relatively easy to attain-particularly as the drifts would become more negligible in comparison with higher dose rates available with medical therapy beams. If the drifts are negligible throughout the container and no control is needed, then, as pointed out in references [1] and [2], sensors could be placed in a pattern between the films, and any number of these arrays can be placed at desired depths in a water for other liquid) phantom. A fast read-out system, in a single irradiation run, could then measure simultaneously the response of each sensor as a function of time to give a dose profile.
}

cobalt- 60 runs with a collimated beam, such as the one having the radial profile shown in figure 1 , will cause the irradiated portion of the water to rise increasingly higher in temperature ${ }^{11}$ compared to the water at larger radial distances. This caused an increased cooling drift which was largely counteracted by increasing the potential across the immersed electrodes. To further decrease the effect of radial heat flow, and to speed the measurements, most investigative studies were made mainly with a broad beam.

\section{Calorimeter Performance}

Figure 10 shows a small portion of a bench test made immediately after completion of the present third model of the calorimeter. The thermistors were at a 2-cm depth in water, and the values of $P_{\mathrm{C}}$ and $P_{\mathrm{J}}$ were 164 and 156 $\mu W$, respectively. Time increases from right to left. The intitial drift shows a rapid cooling rate that was quickly decreased by changing the potential across the electrodes from 0 to $45 \mathrm{~V}$ (the downward spike was caused by the manual adjustment of the potential). Opening a door to the test room caused the shown upward increase in signal that remained constant. Closing the door eliminated the signal that represented about a $12 \mu \mathrm{K}$ equivalent temperature rise of the thermistors. (That the effect might have been caused by electromagnetic signals entering the room was ruled out by tests.) The signal was always repeatable and became less noticeable as the thermistor powers decreased. Two large air ventilators were blowing in the room. A pressure gauge showed that opening the door caused about a $13 \mathrm{~Pa}(0.1 \mathrm{~mm} \mathrm{Hg})$ decrease in air pressure. This may have microscopically increased the spacing between portions of the thermistors and their leads to the films. This would decrease the rate of heat transfer that would cause the thermistors to rise to new equilibrium temperatures.

After closing the door, the cooling drift was again rapidly decreased by increasing the potential to $50 \mathrm{~V}$, and still further by applying $53 \mathrm{~V}$ eleven minutes later. The test was continued for approximately $75 \mathrm{~min}$. Subsequent drifts (not shown) were further decreased by increasing or decreasing the potential as required. The bench test was continued for several days with the recorder running continuously. The recorder showed no sudden changes in drift that would impair the precision of measurements during irradiation. This condition also prevailed in the experimental room during most days of operation; but when large changes in air circulation were felt, noticeable changes in drift were observed.

\footnotetext{
${ }^{11}$ If necessary, this temperature pattern (that results in an increased cooling drift) can be quickly erased by momentarily agitating the water. Every advantage should be taken of the mobility of a liquid and drift control electrodes to bring the calorimeter into operation and to speed the measurements.
} 


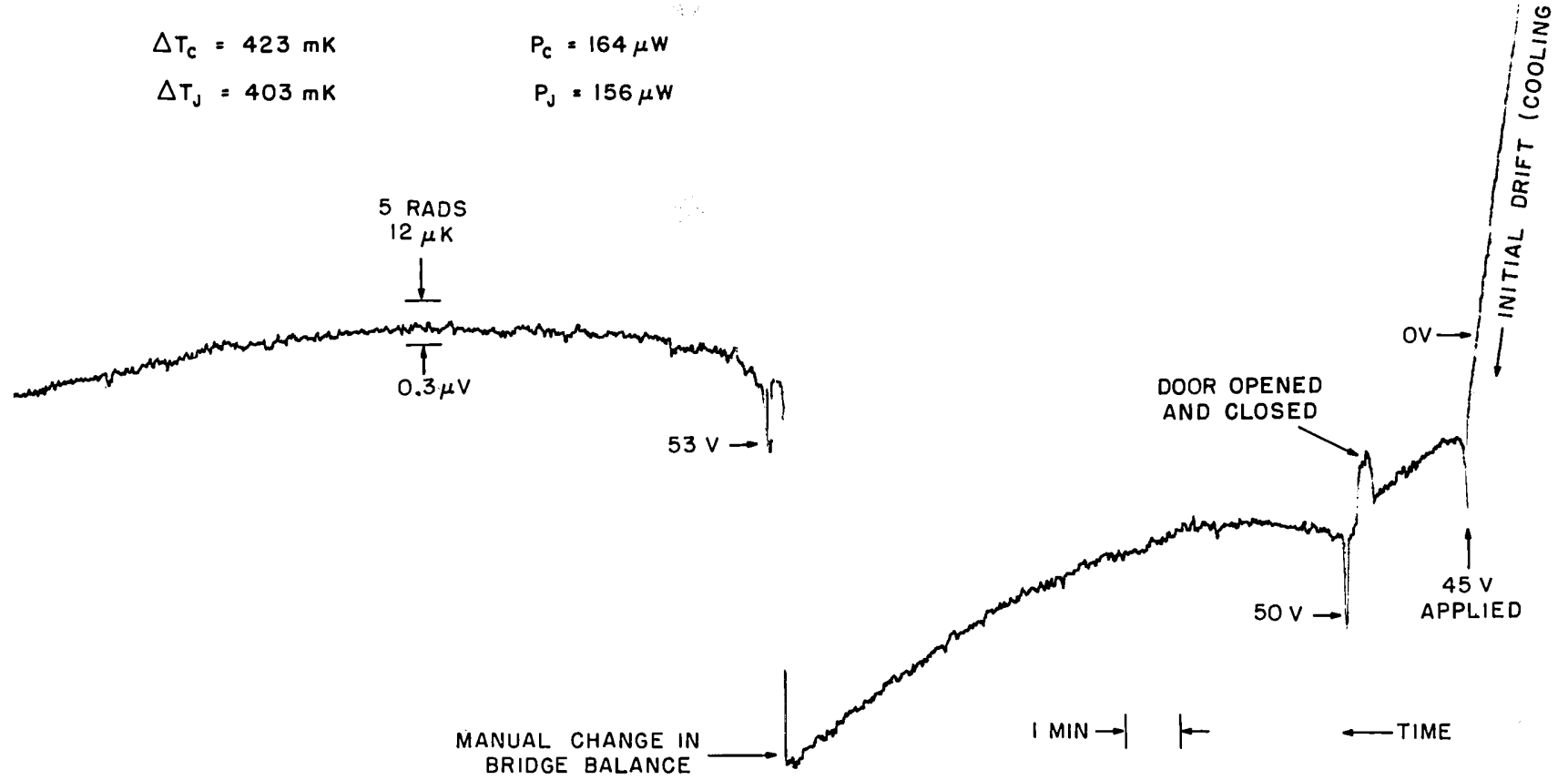

FigURE 10. Early bench test illustrating the calorimetric sensitivity, stability, and rapid control of large temperature drifts.

The rapid initial cooling drift shown in figure 10 is somewhat severe (although controllable, but, as mentioned, the test was made immediately after completion of the calorimeter and before experience with the behavior was gained. Moreover, the procedure followed in subsequent tests, as discussed in the previous section, was different. In this first test, the bath was raised in temperature by 1 degree and agitated for only 3 min (not the $\mathbf{2 0 - 3 0}$ min as recommended). About a half hour later the recording began as shown. The rapid initial cooling was apparently caused by too much heat conduction to the polystyrene rings that lagged too far behind in temperature. Although the applied potentials greatly counteracted this effect, heat conduction to the rings continued and caused the curvatures shown. Even this curvature can be considered small if a typical medical therapy dose rate of $2 \mathrm{~Gy} / \mathrm{min}$ were applied for $1 \mathrm{~min}$. The recorder pen would deflect 40 times greater than the distance indicated by the 5 rads shown. Furthermore, the initial and final drifts would need to be extrapolated only $0.5 \mathrm{~min}$ to the mid-run. When lower dose rates are to be measured over longer periods of time, the quality of measurement would require traces with smaller curvature so that drifts could be extrapolated to the mid-run with precision and accuracy.

Figure 11 shows typical broad beam cobalt- 60 irradiation runs. The dose rate was $1.1 \mathrm{~Gy} / \mathrm{min}(18 \mathrm{mGy} / \mathrm{s})$ ap- plied for 3 minutes. The thermistors were at a 5 -cm depth in water, and the values of $P_{\mathrm{C}}$ and $P_{\mathrm{J}}$ were 9.6 and $9.1 \mu \mathrm{W}$, respectively. The recording was made with an amplifier gain setting which was three times greater than that used to record the test run shown in figure 10. When the initial drift (shown on the right in figure 11) was considered small and predictable, the beam was turned on and $R$ was adjusted around the null (mid-scale) until the beam was turned off after three minutes. The abrupt spikes shown are the result of this manual change in $R$ (the sum total of the pen deflection was 44 times greater than the indicated distance for 7.5 rads). The initial and final drifts were extrapolated toward the mid-position (1.5 min after start of the run for this case). The distance between the two points of intersection of the extrapolated drifts was converted to an equivalent change in $R$ from a chart calibration. These combined with the values of $R$ during the initial and final drifts were used to calculate $\Delta R / R$ for use in eq (7).

The final heating drift in the first run shows that the drift increased slightly compared to the initial drift. Although it can also be considered small, it was decreased before starting the next run. The resistor $R$ was adjusted to move the pen to the mid-position of the recorder chart. The potential across the electrodes was then decreased from 30.5 to $29 \mathrm{~V}$ that decreased the electrical heating power in the $25 \mathrm{~L}$ of water from 157 to 


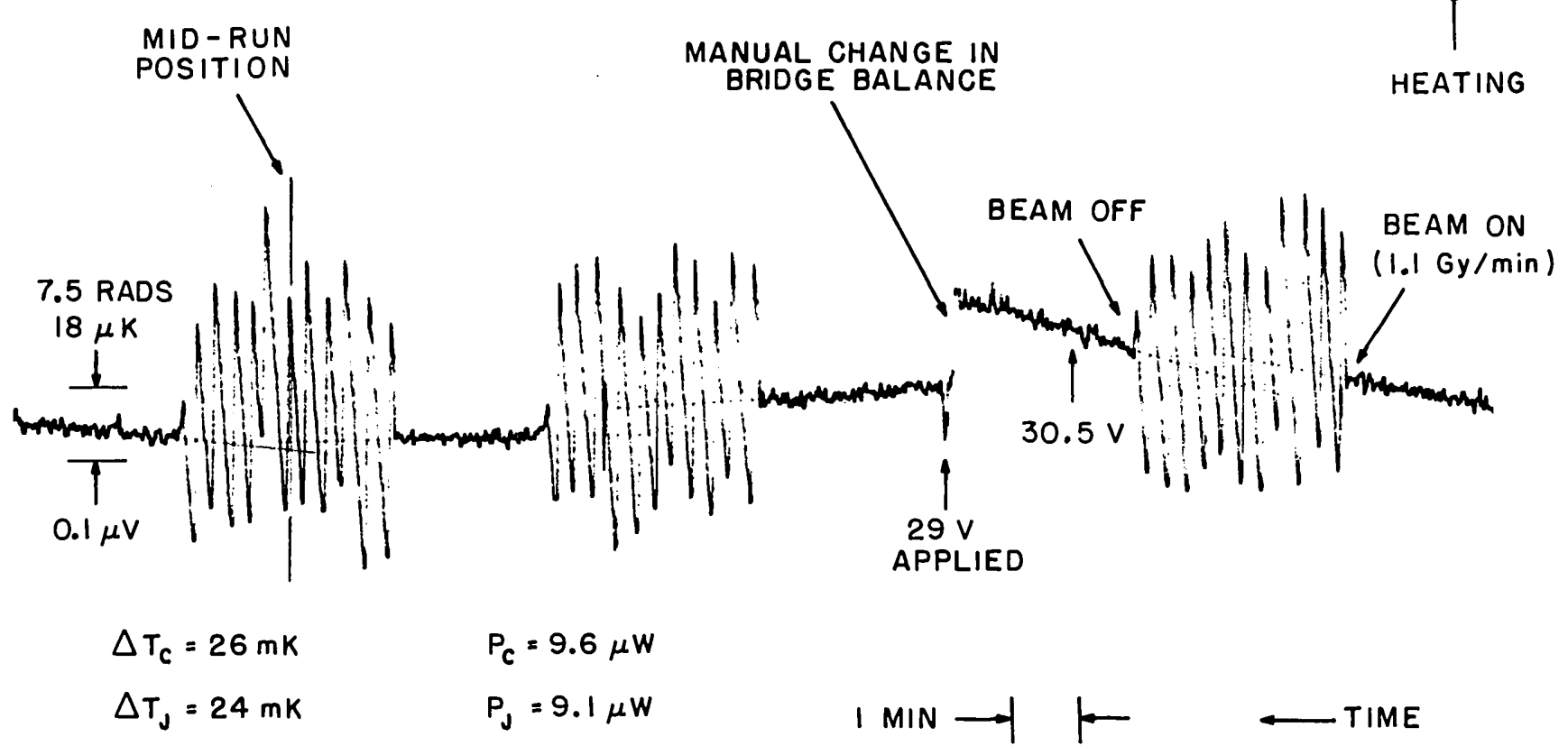

FIGURE 11. Recorder tracings illustrating small and quickly controlled drifts, large signal to noise ratio, and the rapidity of broad beam cobalt-60 measurements.

$146 \mathrm{~mW}$. Several more runs were made without further adjustments in potential.

Observation of all the drifts showed that there was an overall tendency for the drifts to turn slightly upward (heating). This was presumably caused by the broad beam heating of the polystyrene rings that rose three times higher in temperature than the water (as explained previously). Significant heat conduction from the rings (caused from previous runs) was sensed by the thermistors only after a long time had elapsed. This was a desirable behavior because drift control potentials gradually decreased throughout the day. This procedure nearly always permitted runs to be made continuously without loss of calorimeter control which would require reheating and agitation to regain control, with consequent delay. Up to 45 runs were made in a 7 hour period, including the time required to get the calorimeter into operation. Runs were made on approximately $\mathbf{4 0}$ days. The standard deviation for a daily set of measurements varied from 0.3-1.1 percent, with a mean value of 0.6 percent.

\section{Thermistor Power Levels}

The stability of the traces shown in figures 10 and 11 is remarkable when considering the small temperature increments represented by the noise levels shown, compared to that caused by the power levels $\boldsymbol{P}_{\mathrm{C}}$ and $\boldsymbol{P}_{\mathrm{J}}$. Studies with different power levels proved valuable in correcting for the effects of small changes in power during irradiation and in improving the operation of the calorimeter.

In figure 12, the bottom horizontal line (a) represents the equilibrium temperature of the thermistors and water when $P=0$. The horizontal line (b) represents a $24 \mathrm{mK}$ average temperature rise in each thermistor

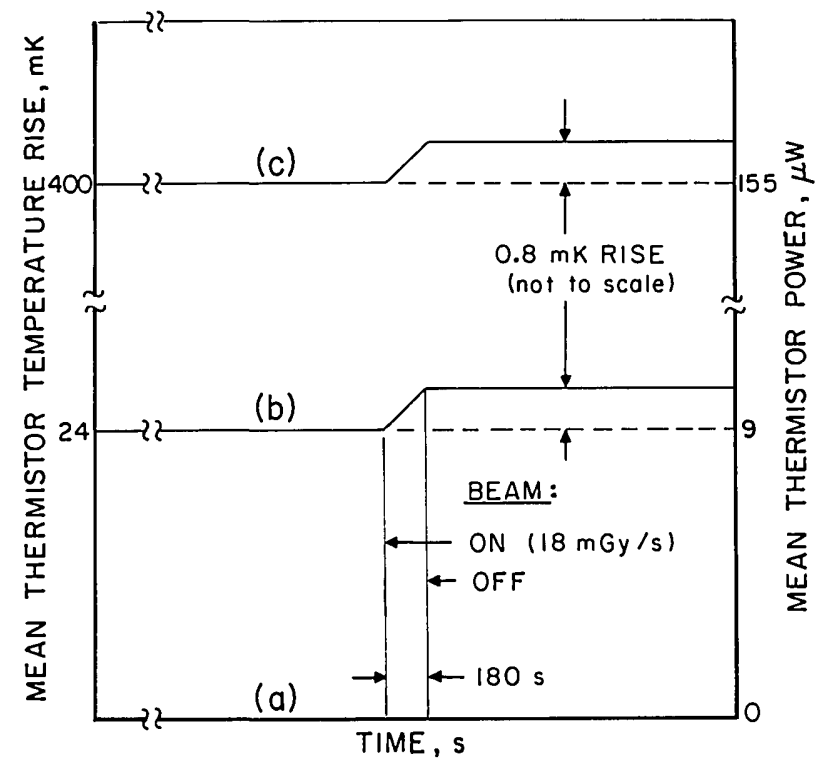

Figure 12. Rise of thermistor temperature levels as a result of electrical power dissipations and beam irradiation. 
when $P=9 \mu \mathrm{W}$ in each $\left(P_{\mathrm{C}}\right.$ and $P_{\mathrm{J}}$ actually differed by 1-7 percent, depending on initial balancing conditions). The figure shows a further temperature rise of $0.8 \mathrm{mK}$ (3.3 percent) as a result of an absorbed dose rate of 1.1 $\mathrm{Gy} / \mathrm{min}$ for three minutes (the predominant irradiation condition used in this investigation). The horizontal line (c) represents a $400 \mathrm{mK}$ temperature rise when $P=155$ $\mu W$, and irradiation further increased the temperature rise by $0.8 \mathrm{mK}(0.2$ percent).

The thermistor temperature rises caused by irradiation were, therefore, very small compared to those caused by electrical power dissipation. This raises an important question as to the power level that would result in optimum performance. Initial investigations were performed at the $155 \mu \mathrm{W}$ level, and then at the $9 \mu \mathrm{W}$ level, which permitted a factor of three increase in amplifier gain. The precision of measurements remained unchanged, about 0.6 percent standard deviation for a daily set of measurements. Measurements over periods of months indicated that operation at the lower power level produced the most stable ratio of output to spurious signal.

During irradiation the thermistor resistances decreased while the bridge balancing resistor ( $R$ in figure 7 ) was manually decreased in value to maintain the output signal near the zero null position. Calculations were made to determine the changes in $P_{C}$ and $P_{J}$ and the resultant temperature changes by use of eq (8). Although these changes produced negligible fractional changes in the (b) and (c) levels (of figure 12), the temperature changes represented much larger fractional changes when they were compared to the $0.8 \mathrm{mK}$ temperature rise caused by the irradiation. The effects are shown in table 2. Column 1 lists the nominal power levels in microwatts. Columns 2 and 3 list the changes in $\boldsymbol{P}_{\mathrm{C}}$ and $P_{\mathrm{J}}$ in picowatts. The changes in average powers are shown in column 4 . The negative sign indicates that the (b) level decreased, reducing the measured fractional resistance change that required a correction of 0.04 percent increase at the $9 \mu \mathrm{W}$ level and a 1.5 percent decrease at the $155 \mu \mathrm{W}$ level. These corrections were calculated from a detailed analysis of the currents and resistances in the Wheatstone bridge circuit before and after the irradiation. They are a good indication of how

TABLE 2: Thermistor electrical power changes and corrections caused from an absorption of $3.3 \mathrm{~Gy}$.

\begin{tabular}{|c|c|c|c|c|}
\hline $\begin{array}{c}\text { Nominal } \\
\text { thermistor } \\
\text { power } \\
(\mu W)\end{array}$ & $\begin{array}{c}\text { Change } \\
\text { in } P_{C} \\
\text { (pw) }\end{array}$ & $\begin{array}{c}\text { Change } \\
\text { in } P_{J} \\
(p W)\end{array}$ & $\begin{array}{c}\text { Change in } \\
\text { average } \\
\text { power } \\
\text { (pW) }\end{array}$ & Correction \\
\hline 9 & 120 & -360 & -120 & 0.04 \\
\hline 155 & 8100 & 50 & 4100 & -1.5 \\
\hline
\end{tabular}

closely the simplified formula (1) describes the real situation, where the power levels change.

Even after applying the above corrections, it was found that the absorbed dose measurements were affected by the power level. This is shown in figure 13. The reason for this behavior is not understood, although recommendations for its possible reduction or elimination will be discussed later. It is speculated that the effect may have been caused by increased thermal coupling between the thermistors and wires with their surroundings during irradiation. This presumably would cause the higher (c) level to drop more than the lower (b) level, and they may not have fully recovered to their initial positions after irradiation to enable an accurate measurement to be made.

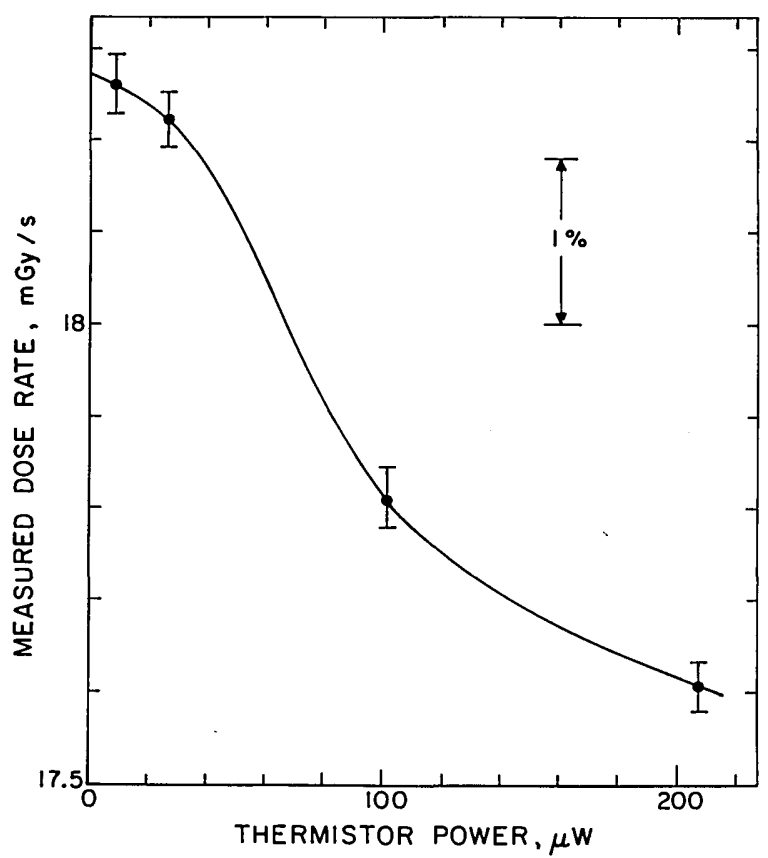

FIGURE 13. Variation of the measured absorbed dose rate versus thermistor electrical power dissipation.

An example of the rate of equilibrium temperature buildup around the thermistors is shown in figure 14 . This is the recorder-pen response when the thermistors were subject to a sudden change in power, by suddenly changing $R_{1}$. The response was primarily a temperature effect when compared to a much faster response when only the balancing resistance $(R)$ was changed. About 90 percent of the temperature change occurred in $2 \mathrm{~s}$, but thereafter the rate of temperature change rapidly diminished. If something similar to this were happening after beam turn-off, it was assumed that this effect (or any other) would disappear for $P=0$. Corrections to this condition were made for all measurements reported in this paper. 


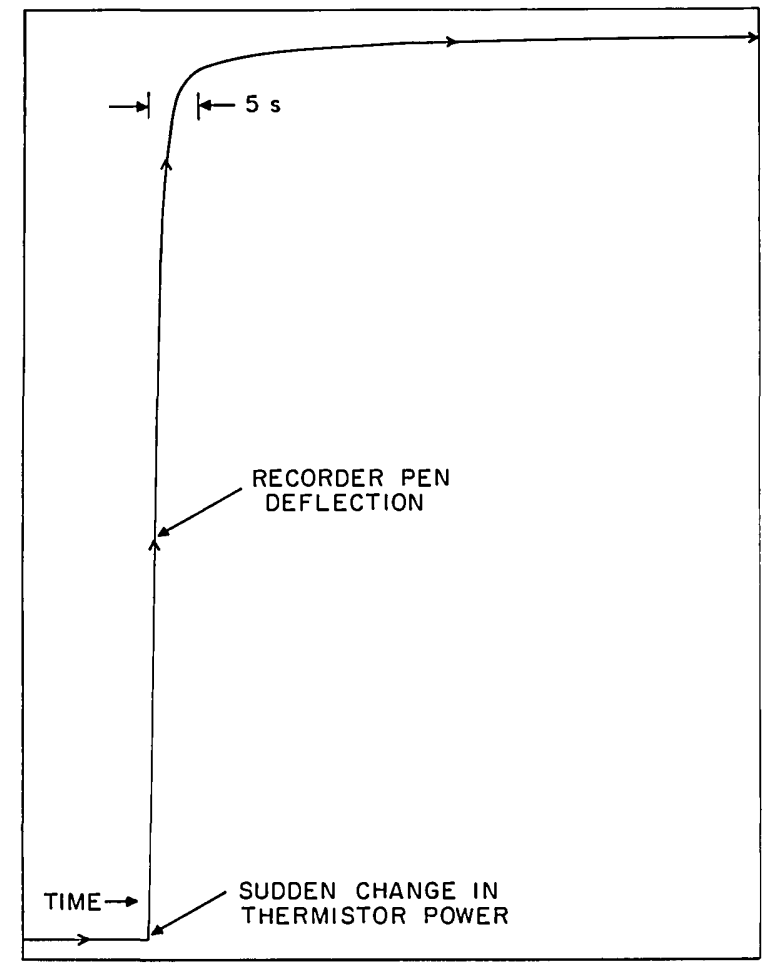

Figure 14. Recorder-pen response showing the rate of relative change in temperature of the thermistors when subject to a sudden change in electrical power dissipation.

\section{Tests in the $C, J$, and $C+J$ Modes}

The results listed in table 3 show the consistency of the absorbed dose measurements with either thermistor or with both in the bridge circuit. The measurement tests were made in distilled water on three separate days; the water was discarded at the end of each day. The sourceto-detector distance was $82 \mathrm{~cm}$, the detector depth was 5 $\mathrm{cm}$, and the cobalt -60 beam was broad. On the first day the thermistor powers were $9 \mu \mathrm{W}$. The first entry in the first row indicates the $\mathrm{C}+\mathrm{J}$ mode (the two-thermistor bridge), while the second and third entries in that row indicate the electrical power dissipations in the thermistors. The second row indicates the one-thermistor $J$ mode. Although the $\mathrm{C}$ thermistor was switched out of the bridge, an auxiliary power supply maintained its $9 \mu \mathrm{W}$ dissipation. The third row still indicates the $\mathrm{J}$ mode, but with $P_{\mathrm{C}}=0$. On the second day, measurements were made at $158 \mu \mathrm{W}$ power levels. On the third day, the power level $\left(P_{\mathrm{J}}\right)$ of the measuring thermistor was $9 \mu \mathrm{W}$. $P_{\mathrm{C}}$ was zero or $160 \mu \mathrm{W}$, the latter causing the $\mathrm{C}$ thermistor temperature rise to increase by an additional 26 percent. The fourth column lists the absorbed dose rate measurements that include 0.07 and 3.4 percent correction factors (i.e., corrected to $P=0$ conditions, using the curve shown in figure 13) when the power levels in the measuring thermistors were 9 and $160 \mu \mathrm{W}$, respectively. Inspection of the results in the fourth and fifth columns indicates the consistency and repeatability in any measurement mode on each of the three days. Therefore, large changes in temperature gradients around the thermistors did not affect the results. These tests also indicated the sharpness of the equilibrium temperature gradients around the thermistors separated by $2.5 \mathrm{~mm}$. A change of temperature rise in either thermistor caused a temperature rise change in the other of only 1.5 percent, as determined by the re-balance of the Wheatstone bridge circuit.

Column 6 shows the number of 2-min irradiation runs. Column 7 shows the total time to complete those runs under the conditions of the nominally applied potential and current ranges shown in columns 8 and 9 , respectively. The data in columns 4 and 9 indicate that the measurements were not affected by electrical current through the water.

\section{Tests for Water Convection}

Results of three observations indicated no evidence of water convection during measurements in the calorimeter described.

In the case of cobalt-60 irradiation (directed vertically downward), the temperature decreases with depth, except from the surface to about $0.5 \mathrm{~cm}$. Consequently, for this radiation source there are, in principle, essentially no buoyant forces trying to cause convection at depths larger than $0.5 \mathrm{~cm}$. However, even in the absence of any irradiation-produced temperature gradients, there is a natural concern as to whether non-uniformity of water temperature in the large $30 \mathrm{~cm}$ cube of water can be such as to set convection in motion. Furthermore, the largest temperature gradients were those caused by electrical power dissipation in the critical regions around the thermistors. Therefore, the possible existence of variations in convective forces at different distances from the thermistors had to be investigated.

The sandwiching polyethylene films themselves form a convective barrier that will delay the onset of convection, or slow it down, compared to isolated point detectors without the films. Such a point detector was also used in the first test for convection.

Figure 15 shows a square ( $152 \mathrm{~mm}$ inside) polystyrene frame (5 mm thick) supporting two $254 \mu \mathrm{m}$ diameter copper wires separated by $25 \mathrm{~mm}$. The wires had about $40 \mu \mathrm{m}$ thick uniform coatings of commercially applied varnish that provided high electrical resistance $\left(>10^{13}\right.$ \&) from water over long periods of time. Figure 16 shows a close-up view of the wires and thermistors near the frame center. The construction was relatively difficult and fragile, and not as effectively insulated over long 
TABLE 3. Absorbed dose measurement test results in the $C$, $J$, and $C+J$ modes.

\begin{tabular}{|c|c|c|c|c|c|c|c|c|}
\hline \multirow{3}{*}{$\begin{array}{c}\text { Mode of } \\
\text { operation }\end{array}$} & \multicolumn{2}{|c|}{ Thermistor } & \multirow{3}{*}{$\begin{array}{c}\begin{array}{c}\text { Dose } \\
\text { rate }\end{array} \\
\text { (mGy/s) } \\
\end{array}$} & \multirow{3}{*}{$\begin{array}{l}\text { Mean } \\
\text { error } \\
\text { of the } \\
\text { mean } \\
(\%)\end{array}$} & \multirow{3}{*}{$\begin{array}{c}\text { Number } \\
\text { of runs }\end{array}$} & \multirow{3}{*}{$\begin{array}{l}\begin{array}{l}\text { Total } \\
\text { time }\end{array} \\
\text { (min) }\end{array}$} & \multirow{3}{*}{$\begin{array}{c}\text { Potential } \\
\text { range } \\
\text { (V) }\end{array}$} & \multirow{3}{*}{$\begin{array}{c}\begin{array}{c}\text { Current } \\
\text { range }\end{array} \\
\text { (mA) }\end{array}$} \\
\hline & \multicolumn{2}{|c|}{ power } & & & & & & \\
\hline & $(\mu W)$ & $(\mu \mathrm{W})$ & & & & & & \\
\hline $\mathbf{C}+\mathbf{J}$ & 9 & 9 & 24.93 & 0.1 & 9 & 40 & $0-0$ & $0-0$ \\
\hline $\mathbf{J}$ & 9 & 9 & 24.83 & .1 & 6 & 25 & $0-0$ & $0-0$ \\
\hline \multirow[t]{2}{*}{$\mathbf{J}$} & 0 & 9 & 25.02 & .4 & 6 & 25 & $0-0$ & $0-0$ \\
\hline & & & $\begin{array}{c}\overline{24.93} \\
\pm 0.2 \%\end{array}$ & & & & & \\
\hline \multicolumn{9}{|c|}{ Water agitated for $8 \mathrm{~min}$, temperature raised } \\
\hline $\mathbf{C}+\mathbf{J}$ & 9 & 9 & 24.97 & 0.2 & 10 & 55 & $10-35$ & $0.5-2$ \\
\hline C & 9 & 9 & 24.87 & .3 & 6 & 35 & $30-20$ & $1.5-1$ \\
\hline $\mathbf{C}$ & 9 & 0 & 25.08 & .4 & 7 & 35 & $10-5$ & $0.5-0.2$ \\
\hline \multirow[t]{2}{*}{$\mathbf{C}+\mathbf{J}$} & 9 & 9 & 24.98 & .2 & 7 & 30 & $0-0$ & $0-0$ \\
\hline & & & $\begin{array}{c}\overline{24.95} \\
\pm 0.3 \%\end{array}$ & & & & & \\
\hline $\mathbf{C}+\mathbf{J}$ & 158 & 158 & 24.95 & 0.7 & 10 & 85 & $35-15$ & $2-1$ \\
\hline $\mathbf{J}$ & 158 & 158 & 24.90 & .7 & 7 & 30 & $0-0$ & $0-0$ \\
\hline \multirow[t]{3}{*}{$\mathbf{J}$} & 0 & 158 & 24.97 & .4 & 6 & 32 & $0-0$ & $0-0$ \\
\hline & & & $\overline{24.93}$ & & & & & \\
\hline & & & $\pm 0.6 \%$ & & & & & \\
\hline $\mathbf{J}$ & 160 & 9 & 24.80 & 0.2 & 10 & 55 & $25-50$ & $1.5-3$ \\
\hline $\mathbf{J}$ & 0 & 9 & 24.90 & .2 & 10 & 55 & 50-35 & $2.5-2$ \\
\hline \multirow[t]{3}{*}{$\mathbf{J}$} & 160 & 9 & 24.98 & .2 & 10 & 40 & $0-0$ & $0-0$ \\
\hline & & & $\overline{24.90}$ & & & & & \\
\hline & & & $\pm 0.2 \%$ & & & & & \\
\hline
\end{tabular}

periods of time as with use of the films; nevertheless, the detector was sufficiently good for its intended purpose. Care had to be used in passing this detector through the water surface so that the surface tension would not damage the delicate structure.

The large wires are shown twisted together after having been cut. On each side of the two twisted junctions, small varnish sections (separated by about $2.5 \mathrm{~mm}$ ) were scraped away with a surgical blade to permit attachments of the Pt-Ir wires fused to the two $0.25 \mathrm{~mm}$ diameter bead thermistors. Soldering the wires caused melting of the varnish, but the electrical resistance across each twisted junction remained high (about $5 \times 10^{13} \Omega$ ). High electrical resistance was needed because the thermistors were to be positioned in opposite arms of the Wheatstone bridge circuit.

The bare $25 \mu \mathrm{m}$ diameter Pt-Ir wires and the seemingly porous thermistor beads were covered with several coatings of silicone rubber to electrically insulate them from water. The final variable coating thicknesses were about $0.05-0.13 \mathrm{~mm}$ on the bare wires, and about 0.13

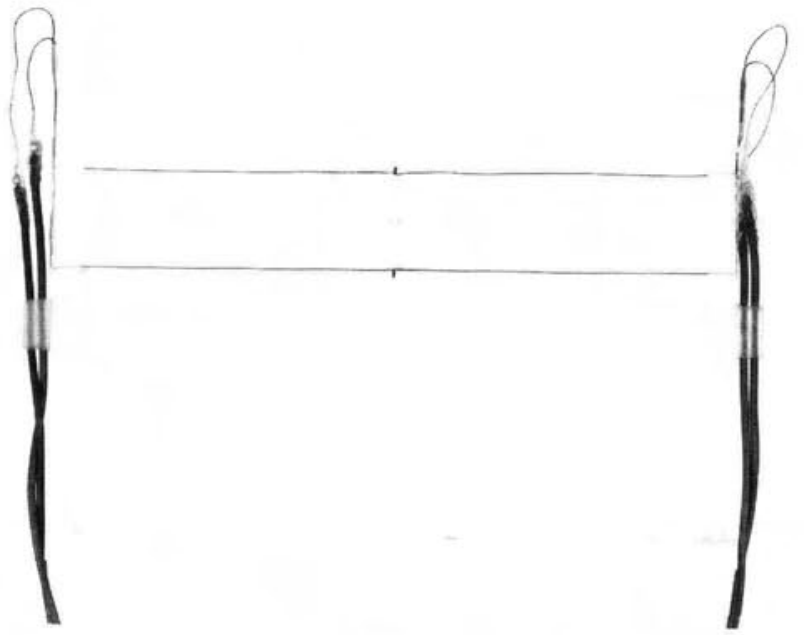

FIGURE 15. Photograph showing mounting of two thermistors with insulative leads. 

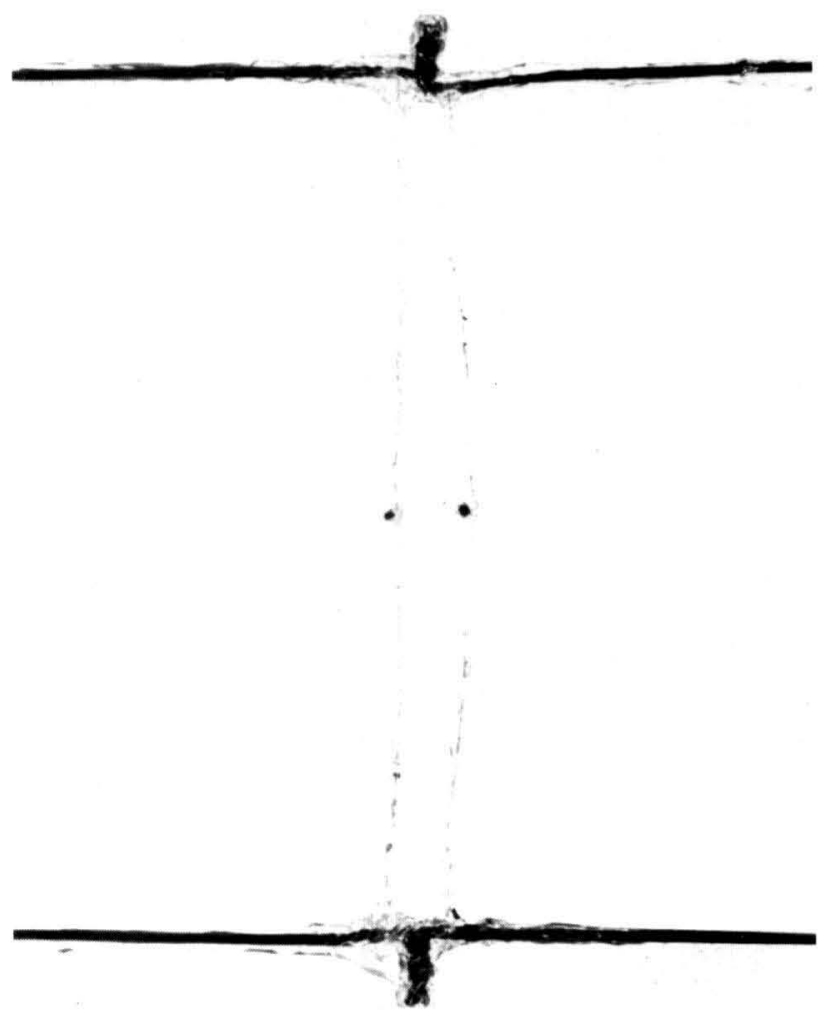

Figure 16. Close-up photograph of the two insulated $0.25 \mathrm{~mm}$ diameter bead thermistors and leads.

mm around the beads. Compared to the uniformly thin polyethylene film insulators (which were much better), large uneven coating thicknesses could produce larger excess generated heat during irradiation that would be difficult to account for by calculation.

These thermistors $\left(\mathrm{C}^{\prime}\right.$ and $\left.\mathrm{J}^{\prime}\right)$ were horizontally positioned at a depth of $6 \mathrm{~cm}$ in distilled water and were separated by $1.5 \mathrm{~mm}$ at the time of the measurements. Measurements were made in this condition and also by placing a stretched $2 \mu \mathrm{m}$ plastic film above the thermistors at a distance of $2.5 \mathrm{~mm}$ and then at $8.7 \mathrm{~mm}$. The film was mounted on a polystyrene frame similar to that shown in figure 15. This convective barrier would presumably have had an effect on any convection that existed.

There were two modes of operation. In the $\mathrm{C}^{\prime}+\mathrm{J}^{\prime}$ mode, the two thermistors were located in opposite arms of a bridge circuit. Plots were made of the measured resistances, $r_{C^{\prime}}$ and $r_{\mathrm{J}^{\prime}}$, as a function of their electrical power dissipations, $P_{\mathrm{C}^{\prime}}$ and $\boldsymbol{P}_{\mathrm{J}^{\prime}}$. $\boldsymbol{P}_{\mathrm{C}^{\prime}}$ varied from 8-530 $\mu \mathrm{W}$, while $P_{\mathrm{J}}$, varied from $12-720 \mu \mathrm{W}$, which produced maximum thermistor temperature rises of 0.8 and $1.5 \mathrm{~K}$, respectively. Measurements were also made in the $\mathrm{C}^{\prime}$ mode where $\boldsymbol{P}_{\mathrm{J}}$, was zero, while $\boldsymbol{P}_{\mathrm{C}^{\prime}}$ was again varied from 8-530 $\mu W$.
If a large onset of convective motion had occurred, then it could be expected that an abrupt change in the resistance versus power curves (such as in fig. 9) would have been observed. An onset of convection would have had a sudden cooling effect on the thermistors that would have caused the curves to have an abrupt upward curvature. No significant change in slope was observed.

However, there may have been minute convective currents confined to the immediate vicinity of the thermistors where there were sharp temperature gradients. In principle, such highly confined convection has essentially little or no effect on the measurements of resistance or absorbed dose.

The second test was mainly to detect if there was any existing motion of the water that affected the measurements. The structure used is shown in figure 17. The detector was the one first described, the two thermistors sandwiched between films. $P_{\mathrm{C}}$ and $P_{\mathrm{J}}$ were 9 $\mu \mathrm{W}$, which produced temperature rises of only $24 \mathrm{mK}$. The front and rear distances of the barriers from the plane of the thermistors (at a $5 \mathrm{~cm}$ depth) were 17 and 22 $\mathrm{mm}$, respectively. Each barrier consisted of a $2 \mu \mathrm{m}$ thick plastic film stretched on a polystyrene ring, $15 \mathrm{~cm}$ inside diameter. Three plastic rods spaced each barrier parallel to the detector plane. The rods permitted flow of water between the planes during agitation. They also permitted the drift control electrical current to pass freely between those planes. Measurements of absorbed dose rates (on the same day) were made with and without the convection barriers in position. The results are shown in table 4.

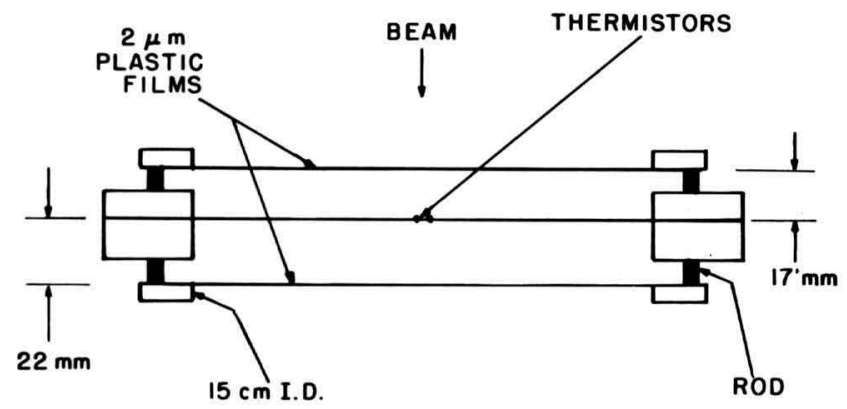

FIGURE 17. Configuration of the detector and $2 \mu \mathrm{m}$ plastic film convection barriers.

TABLE 4. Results of second water convection test.

\begin{tabular}{c|c|c|c|c}
\hline \hline $\begin{array}{c}\text { Convection } \\
\text { barriers }\end{array}$ & $\begin{array}{c}\text { Dose rate } \\
(\mathrm{mG} / \mathrm{s})\end{array}$ & $\begin{array}{c}\text { Difference } \\
(\%)\end{array}$ & $\begin{array}{c}\text { Mean } \\
\text { error } \\
(\%)\end{array}$ & $\begin{array}{c}\text { Number } \\
\text { of runs }\end{array}$ \\
\hline In & 18.39 & 0.20 & 0.18 & 12 \\
Out & 18.43 & & 0.16 & 12 \\
\hline
\end{tabular}


Placement of the barriers in position would have decreased any existing water convection at those positions. Because there was no significant difference in the dose rate measurements, it was concluded from this test that convection in the vicinity of those barriers was insignificant or non-existent.

The third and most sensitive and convincing test, which at least indicates the absence of moderate water convection, is the recorder-pen tracings shown in figures 10 and 11 . The indicated average temperature rises of the thermistors above that of the water are 413 and 25 $\mathrm{mK}$, respectively. Compared to the noise levels of only several microdegrees, these gave differential temperature ratios of roughly 100,000 to one and 10,000 to one in figures 10 and 11 , respectively. These large ratios and the existence of the sharp temperature gradients around the thermistors would seem to have created a sensitive condition for detecting turbulent motion. Large changes would have disturbed the temperature gradients which would have caused large disturbances in the recorder output. Instead, long and stable drifts were observed. From these observations, it was concluded that the sharp temperature gradients around the thermistors produced insignificant or non-existent local turbulence and that these conditions extended to much larger distances.

It is worth repeating that on a few occasions the tracings did show sudden changes which were believed to have been caused by sudden changes in air circulation which produced air pressure changes in the mesurement room. However, it was only on one out of 40 measurement days that the stability was considered impaired enough (only during the large thermistor power dissipation of $155 \mu \mathrm{W}$ ) so that the measurements made on that day were ignored. Possible ways to eliminate the air pressure effect will be suggested later in this paper.

\section{Effects of $\mathrm{N}_{2}$ and $\mathrm{O}_{2}$ Saturated Water}

It is well-known theoretically that irradiation of water saturated with oxygen induces production of hydrogen peroxide [25,26]. If oxygen were the only gas initially present in the water, then it would aid in producing a positive heat defect which means that it would contribute to a decrease in calorimeter response. It is also theoretically expected that the heat defect would be less significant for the case of water initially saturated with nitrogen, replacing the oxygen. An experimental test was made to determine whether a significant difference in the measured absorbed dose rate could be detected. The results are shown in table 5 .

A set of measurements was made on three different days. Each morning the calorimeter was refilled with newly drawn once-distilled water. Column 1 indicates the gas used to agitate the water. The gas flow rate near the four vertical edges in the water in the tank was about $1.5 \mathrm{~L} / \mathrm{min}$. Column 2 indicates the duration of agitation. Column 3 shows the measured absorbed dose rates (corrected for cobalt- 60 decay), and column 4 shows the differences in measured results. The percent mean errors of the mean and the number of runs are shown in columns 5 and 6 , respectively. Column 7 indicates the continued rate of gas flow (after agitation) in the space between the two calorimeter enclosures to prevent air from diffusing back onto the water surface during measurements. The duration of each run was three minutes.

The results show that (for the conditions described) there was no significant difference in measurements of absorbed dose rate as a result of the water pre-agitated with oxygen or nitrogen. However, it is not concluded that an effect caused by hydrogen peroxide production did not exist. It was subsequently pointed out [27] that if the water still contained initial concentrations about $10^{-6} \mathrm{~mol} / \mathrm{L}$ (or larger) of dissolved hydrogen and oxygen, then a 3.0 percent reproducible exothermic reaction (increase in heat) would have been included in the measurements. The nitrogen used to pre-agitate the water was classified: "High purity, oxygen-free, $<5$ ppm."

More experimentation is necessary. New apparatus would have to be constructed for use of triply distilled water saturated separately with oxygen, nitrogen, or hydrogen. Water saturated with hydrogen is believed to have a virtually zero heat defect [28].

\section{Effects of Water Impurities}

Important critical questions concerning the effects of water impurities and calorimetric materials must be investigated. Once-distilled water was used for beam calibration measurements. It was inexpensive and readily available in large quantities, which were important practical considerations. However, was the water from the still pure enough so that radiation induced chemical effects were negligible? Also, what are the effects of dissolved organics from the immersed calorimetric materials? The calorimeter was used to answer these complex questions as much as possible.

Figure 18 and table 6 show results of investigations with liquids of widely different impurities. Column 1 identifies the liquid and column 2 identifies the curves shown in the figure. Column 3 indicates the gas used to agitate the water prior to the start of measurements. Figure 18 shows curves of the "apparent" absorbed dose rate (absorbed dose plus chemically induced effects) as a function of the accumulated calorimetric response up to $150 \mathrm{~Gy}$. In reality, all absorbed dose measurements reported in this paper were determined from 
TABLE 5. Results with $\mathrm{N}_{2}$ and $\mathrm{O}_{2}$ saturated water.

\begin{tabular}{|c|c|c|c|c|c|c|}
\hline Gas & $\begin{array}{l}\text { Duration of } \\
\text { agitation } \\
\text { (min) }\end{array}$ & $\begin{array}{l}\text { Dose rate } \\
\text { (mGy/s) }\end{array}$ & $\begin{array}{c}\text { Difference } \\
(\%)\end{array}$ & $\begin{array}{c}\text { Mean } \\
\text { error } \\
(\%)\end{array}$ & $\begin{array}{l}\text { No. of } \\
\text { runs }\end{array}$ & $\begin{array}{l}\text { Gas over- } \\
\text { flow rate } \\
\left(\mathrm{cm}^{3} / \mathrm{min}\right)\end{array}$ \\
\hline $\begin{array}{l}\mathrm{N}_{2} \\
\mathrm{O}_{2}\end{array}$ & $\begin{array}{l}17 \\
22 \\
\end{array}$ & $\begin{array}{l}18.40 \\
18.34 \\
\end{array}$ & -0.3 & $\begin{array}{l}0.18 \\
0.14 \\
\end{array}$ & $\begin{array}{r}8 \\
17 \\
\end{array}$ & 30 \\
\hline $\begin{array}{l}\mathrm{N}_{2} \\
\mathrm{O}_{2}\end{array}$ & $\begin{array}{l}33 \\
33\end{array}$ & $\begin{array}{l}18.39 \\
18.38\end{array}$ & -0.05 & $\begin{array}{l}0.11 \\
0.07\end{array}$ & $\begin{array}{l}12 \\
16\end{array}$ & 70 \\
\hline $\begin{array}{l}\mathrm{N}_{2} \\
\mathrm{O}_{2}\end{array}$ & $\begin{array}{l}67 \\
67\end{array}$ & $\begin{array}{l}18.31 \\
18.34\end{array}$ & 0.2 & $\begin{array}{l}0.09 \\
0.14\end{array}$ & $\begin{array}{l}16 \\
16\end{array}$ & 120 \\
\hline
\end{tabular}

TABLE 6. Liquid parameters and results.

\begin{tabular}{|c|c|c|c|c|}
\hline \multirow[b]{2}{*}{ Liquid } & \multirow[b]{2}{*}{ Curve } & \multirow{2}{*}{$\begin{array}{c}\text { Agitation } \\
\text { gas }\end{array}$} & \multicolumn{2}{|c|}{ Electrical resistivity } \\
\hline & & & $(\mathbf{k} \mathbf{Q - c m})$ & $\begin{array}{l}\text { Approx. max. } \\
\text { daily change } \\
\text { (\%) }\end{array}$ \\
\hline Distilled water & 1 & $\mathrm{O}_{2}-\mathrm{N}_{2}$ & $100-800$ & -100 \\
\hline Tap water & 2 & $\mathrm{~N}_{2}$ & 4 & 30 \\
\hline $10^{-2} \mathrm{M} / \mathrm{L}$ iso-propyl alcohol & 3 & Air $-N_{2}$ & $200-600$ & -100 \\
\hline $10^{-5} \mathrm{M} / \mathrm{L}$ cadmium sulfate & 4 & Air & 100 & -80 \\
\hline$" \quad " \quad "$ & 1 & $\mathbf{N}_{2}$ & 100 & -70 \\
\hline $10^{-3} \mathrm{M} / \mathrm{L}$ sodium formate & $5-5^{\prime}$ & $\mathrm{N}_{2} \cdot \mathrm{O}_{2}$ & 200 & -40 \\
\hline$" \quad " \quad "$ & $6 \cdot 6^{\prime}$ & $\mathrm{O}_{2} \cdot \mathrm{N}_{2}$ & 300 & -60 \\
\hline
\end{tabular}

measurements of heat rise that resulted from all irradiation effects. For all results shown in figure 18, the source-to-detector distance was $1 \mathrm{~m}$, the detector depth in water was $5.0 \mathrm{~cm}$, the cobalt- 60 beam was broad, and the irradiation times were $3 \mathrm{~min}$, resulting in an absorbed dose of $3.3 \mathrm{~Gy}$ in distilled water (the points are not shown for the sake of clarity). Also, in all cases the liquid was discarded at the end of a day of measurements. Then (except after using distilled water) the drift control immersion plates were removed, thoroughly cleaned, and the tank was refilled twice-agitated, and drained during agitation.

Curve (1) in figure 18 indicates that for distilled water there was no detectable change in measurements. ${ }^{12}$ Column 4 of table 6 indicates a large variation in the water

\footnotetext{
${ }^{12}$ Examination of all data, however, roughly suggests that there may have been a small increase below $10 \mathrm{~Gy}$. Several attempts were made to further explore this region by decreasing the duration of the runs from three minutes to one minute, to get better resolution of measurements. The results were inconclusive.
}

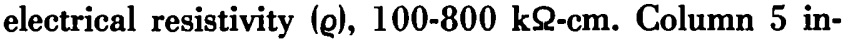
dicates that the value of $\varrho$ decreased by approximately 100 percent during measurements throughout the day. That irradiation is not the cause is evident from figure 19 where measurements of $\varrho$ were made as a function of time in the absence of and then with irradiation on a new supply of distilled water. With $23 \mathrm{~V}$ across the electrodes, the initial and final current and power ranges were 4.0-4.7 $\mathrm{mA}$ and $90-110 \mathrm{~mW}$, respectively.

Curve (2) in figure 18 shows results of repeatable measurements with tap water on two separate days. The initial calorimeter response was 35 percent higher than with distilled water, but rapidly decreased to within 1 percent of distilled water between 60 and $150 \mathrm{~Gy}$. The water was noticeably discolored (muddy in appearance as a result of pipe supply maintenance). The formation of many bubbles on the immersed surfaces indicated that the tap water was very gassy (bubble formation was not evident with distilled water). The initial value of $\varrho$ was 4 $\mathrm{k} \Omega-\mathrm{cm}$, lower than the average for distilled water by ap- 


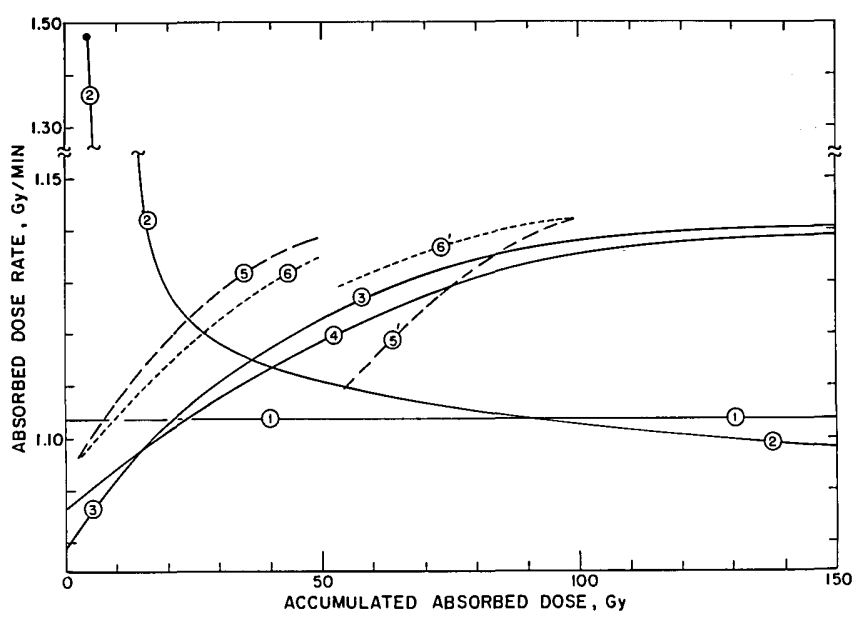

Figure 18. Measured dose-rate as a function of accumulated dose, for: (1): distilled water, or cadmium sulfate solution $\mathrm{N}_{2}$ saturated; (2): tap water; (3): iso-propyl alcohol solution $N_{2}$ or air saturated; (4): cadmium sulfate solution air saturated; (5)-(5)' : sodium formate solution $\mathrm{N}_{2}-\mathrm{O}_{2}$ saturated; (6)-(6)' : sodium formate solution $\mathrm{O}_{2}-\mathrm{N}_{2}$ saturated.

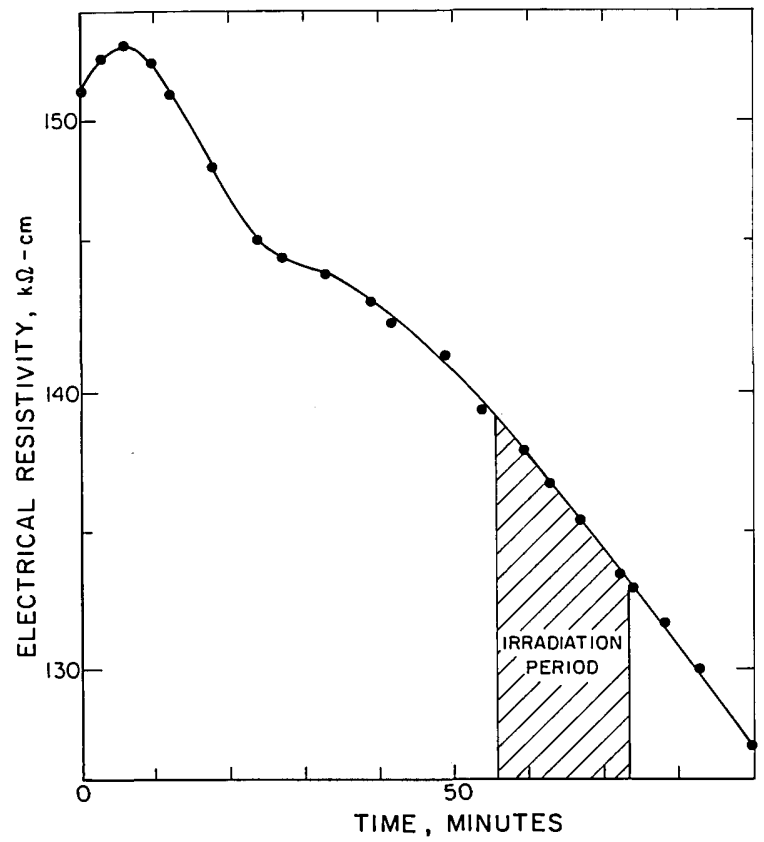

FigURE 19. Change in water electrical resistivity in the absence of and during irradiation.

proximately a factor of 100 . The value of $\varrho$ increased by approximately 30 percent during the measurements. To efficiently control the drifts in water with such a low resistivity, the electrical components in the temperature drift controller (figure 3 ) had to be replaced.

Curve (3) of figure 18 shows results of complicated reactions $[25,26]$ due to irradiation of a solution of $10^{-2}$ $\mathrm{mol} / \mathrm{L}$ of iso-propyl alcohol. On one day air was used to agitate the liquid, and on another day the high purity nitrogen was used. The results showed no significant difference between the measurements. Initially, a heat deficiency (relative to the distilled water) was observed, but it diminished and then a heat excess gradually increased to 3.4 percent at $150 \mathrm{~Gy}$.

Curve (4) shows similar results of one day of measurements using a radical scavenger [25] solution of $10^{-5} \mathrm{~mol} / \mathrm{L}$ of cadmium sulfate added to the distilled water preagitated with air. However, when nitrogen was used on another day, the results were the same as with distilled water, table 6 .

Curves (5) and (5') show results with a $10^{-3} \mathrm{~mol} / \mathrm{L}$ sodium formate solution preagitated with nitrogen and oxygen, respectively. The reaction of the solution with irradiation results in the formation of hydrogen peroxide. Initially, a small positive heat defect was observed, but it disappeared near $10 \mathrm{~Gy}$ where a negative heat defect grew to an extrapolated value near 4 percent at $150 \mathrm{~Gy}$. Curves (6) and (6') show results on another day when the agitation was with oxygen and nitrogen, respectively.

Further studies were carried out to determine the effect of storing distilled water in various containers. The water supply was drawn from a $100 \mathrm{~L}$ stainless-steel reservoir. During the course of the mesurement, it was noticed that the bottom of the reservoir was covered with a hard layer of residue. The reservoir was removed, thoroughly scrubbed with steel and nylon brushes, and rinsed numerous times with distilled water. Although the value of $\varrho$ increased by a factor of eight, no noticeable difference was observed in the measured absorbed dose rate. Occasionally, the water in the reservoir was agitated while it was being completely drained and then refilled.

The water drawn from this reservoir was stored in three types of containers prior to use in the calorimeter. Container \#1 was a new $25 \mathrm{~L}$ polyethylene jug. The water used from this jug was always replaced in that jug. Measurements in this water extended over a period of seven months-a period long enough for organic materials from the polyethylene to dissolve into the water. Container \#2 was a $25 \mathrm{~L}$ used glass jug. Numerous rinses with solvents an solutions of sodium hydroxide, sodium dichromate and sulfuric acid, followed by numerous rinses with distilled water, failed to remove noticeable internal deposits of unknown composition. Nevertheless, use of this jug was considered of value in view of the objective of the investigation. Water stored in this jug was also replaced in that jug after use in the calorimeter tank. Container \#3 was a new $25 \mathrm{~L}$ glass jug that was washed with hot solutions of detergent soap and rinsed numerous times with hot tap water and then numerous times with distilled water. Water stored in this container was always discarded after it was used in the calorimeter tank. Only the results of measurements in 


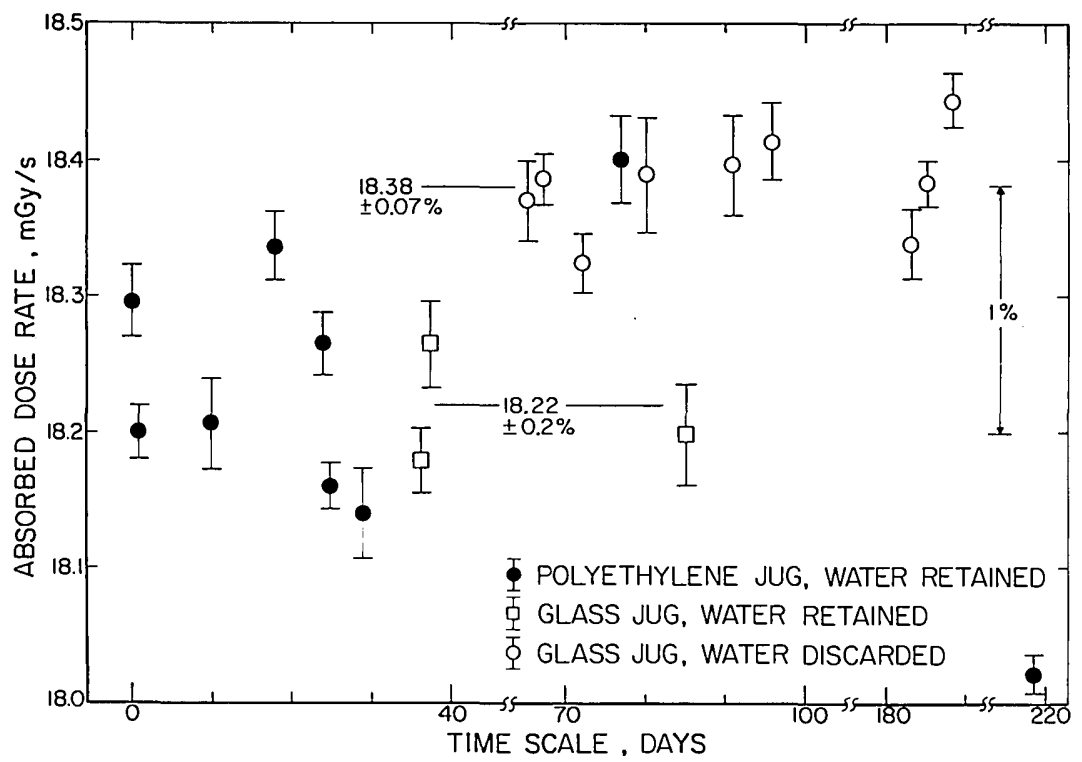

FIGURE 20. Comparison of broad-beam absorbed dose measurements in water stored for different durations in three different containers.

water from this container (\#3) were used for the final reported beam calibrations.

The results for broad beam irradiation are shown in figure 20, where the absorbed dose rate (corrected for cobalt- 60 decayl is plotted as a function of time. The uncertainties are mean errors of the mean. The data shown by the closed circles were from measurements in water from container \#1. The water was pre-agitated with air prior to the measurement results shown by the data points from 0-29 days, whereas nitrogen was used prior to the measurement results made on the 77 th and 219 th day. The mean value of those nine data groups was $18.23 \mathrm{mGy} / \mathrm{s}$, with a mean error of 0.2 percent. Measurement results in water from container \#2 (shown by the squares) were made on the 36 th and 37 th day (water pre-agitated with air), and also on the 85th day (water pre-agitated with nitrogen). The mean value of the three data groups was $18.21 \mathrm{mGy} / \mathrm{s}$, with a mean error of 0.2 percent. The results show no significant difference between the two sets of data that have a mean value of $18.22 \pm 0.2$ percent for the 12 data groups. The nine data groups shown by the open circles extending from the 65th to 186th day (water pre-agitated with nitrogen) are from measurements in water from container \#3. The range of the data points in this group is 0.7 percent, which indicates good reproducibility of results over a period of 121 days. The mean value of those nine data groups was $18.38 \mathrm{mGy} / \mathrm{s}$, with a mean error of 0.07 percent. The results indicate that the measurements were not critically dependent on the cleanliness or material of the storage containers. The constancy of successive runs throughout a day indicated a negligible effect of dissolved organics from the sandwiching films into the immediate surrounding water.

\section{Results for Collimated Beam}

The mean value of nine sets of determinations on nine different days was $17.21 \mathrm{mGy} / \mathrm{s}$, with a standard error of the mean of 0.07 percent. The final result was 17.21 $\mathrm{mGy} / \mathrm{s} \pm 0.4$ percent combined uncertainty. The conditions of the measurements (corrected for cobalt-60 decay) were for the once distilled water pre-agitated with high purity nitrogen (oxygen free, $<5 \mathrm{ppm}$ ), detector depth at $5 \mathrm{~g} / \mathrm{cm}^{2}$, source-to-detector distance of $1 \mathrm{~m}$, and for the collimator size that produced the beam profile shown in figure 1 . These were the same conditions that were used to calibrate the same beam with the graphite calorimeter [8]. Conversion of those results to water [9] gave an absorbed dose rate of $16.63 \mathrm{mGy} / \mathrm{s} \pm$ 0.6 percent combined uncertainty. The result with the water calorimeter is 3.5 percent higher than this value.

The higher apparent absorbed dose rate in once distilled water appears to be in approximate agreement with a recent result. Measurements in double distilled and in de-ionized water (in a copy of the calorimeter described in this paper) were 3.8 percent higher when the measurements were compared with those determined with an ionization chamber [29]. This same general conclusion also appears to be the case for comparison for measurements in a small cell alternately containing double distilled water and a Fricke solution [30]. 


\section{Corrections and Uncertainties}

A negligible uncertainty was assigned to the specific heat of water that has listed values (versus temperature) to five figures in reference [7]. Corrections and uncertainties in measurement of source-detector distance and the $5 \mathrm{~cm}$ linear depth in water were negligible because of the accuracy of the optical sighting and micrometer measurements. However, a 0.05 percent correction was required to correct all absorbed dose measurements to a mass depth of $5 \mathrm{~g} / \mathrm{cm}^{2}$. Uncertainties in the calibrated temperature probe $(1 \mathrm{mK}$ temperature resolution display) needed to measure the sensitivities of the thermistors were considered to be negligible.

Table 7 lists larger uncertainties from sources shown in column 1 . The second column lists statistical uncertainties $s_{i}$ in terms of standard deviations of random measurements, and the numbers in parentheses are the corresponding numbers of degrees of freedom. The largest statistical uncertainty is 0.2 percent for the reproductibility of measurements in new supplies of distilled water. The uncertainty in determining the sensitivity of either the $C$ or the $J$ thermistor is listed as 0.1 percent. Ionization measurements in a water phantom showed that the expanded polystyrene and aluminum foil of the calorimeter lid decreased the absorbed dose measurements by 0.34 percent. This correction was made and a 0.05 percent uncertainty was assigned.

TABLE 7. Uncertainties in the absorbed dose rate measurements.

\begin{tabular}{l|c|c}
\hline \multicolumn{1}{c|}{ Source } & \multicolumn{2}{|c}{ Estimated uncertainty (\%) } \\
\cline { 2 - 3 } & $\begin{array}{c}\text { Statistical } \\
\text { (degrees of } \\
\text { freedom) } \\
s_{i}\left(\nu_{j}\right)\end{array}$ & Other \\
\hline Reproducibility of water & $0.2(8)$ & $u_{j}$ \\
\hline Sensitivity of C-thermistor & $0.1(3)$ & 0.1 \\
Sensitivity of J-thermistor & $0.1(3)$ & 0.1 \\
Effect of lead resistances & & 0.05 \\
Beam attenuation of calorimeter lid & $0.05(5)$ & 0.05 \\
Beam exposure timing & & 0.05 \\
Extrapolation to zero thermistor power & & \\
Polyethylene films & & 0.3 \\
\hline
\end{tabular}

Combined uncertainty $=\sqrt{\Sigma_{i}^{2}+\Sigma \mu_{j}^{2}}=0.4 \%$
Column 3 lists the uncertainties $\mu_{j}$, which are believed to be reasonable estimates of other non-statistical uncertainties, to be treated as if random in character. A 0.1 percent uncertainty was assigned for this type of uncertainty in determining the sensitivity of either the $C$ or the $J$ thermistor. The Pt-Ir leads fused to each thermistor bead had a calculated resistance of $9.5 \mathrm{ohms}$, and the additional copper signal leads raised the resistance to 10.7 ohms external to the nominal $3 \mathrm{k} \Omega$ resistance within the beads. These external resistances decreased the fractional change in resistance of each thermistor arm which caused a decrease in the fractional measured change in the bridge-balancing resistor arm. An analysis showed that the results of the measurements had to be increased by 0.36 percent, and a 0.05 percent uncertainty was assigned. A 0.05 percent uncertainty was also assigned to the beam exposure time and to the thermal effects of the polyethylene films. A 0.3 percent uncertainty was assigned for extrapolation to zero thermistor power (from fig. 13).

These initial measurements gave no conclusive evidence for assigning corrections or uncertainties for heat defects for the experimental conditions described.

The combined uncertainty was calculated by using a recently recommended procedure [31]. That uncertainty was obtained by combining in quadrature the uncertainties shown in table 7 . The combined uncertainty was calculated to be 0.4 percent, excluding effects of the radiation chemistry of water. Treating the combined uncertainty as if it were a mean error, it can be multiplied by a factor of 2 to obtain an overall uncertainty of 0.8 percent. For the present, this overall uncertainty is rounded upward, and an uncertainty of about 1 percent is assigned to absorbed dose determinations with the water calorimeter in the NBS cobalt- 60 gamma-ray beam, excluding uncertainty arising from radiation chemistry of water.

\section{Discussion}

An interesting result is that the absorbed dose rate measured in water was 3.5 percent higher than the results converted from measurements with a graphite calorimeter. The sources of this significant difference cannot at present be explained with assurance. The theoretical 3.0 percent exothermic effect, that could have been produced by production of hydrogen peroxide, offers the best lead to explain most of the difference. This will be explored experimentally and theoretically. Also, there still remains an unresolved problem in calorimetry concerning the effects of vacuum gaps in calorimeters made of solid materials. Recent experimental data for 12-30 MeV electrons indicate that the gap effects, in a copy of the NBS graphite calorimeter, vary in the range 
of \pm 0.7 percent, depending on the beam energy [32]. Speculative reasoning would seem to indicate that the gaps surrounding the core would result in a smaller response than the water calorimeter that has no such gaps. This would provide a partial explanation of the difference. Further experimental data, that will include results under different irradiation conditions, will be available from use of replicas of calorimeters that are now in operation or are being constructed at other institutions. Also in progress by others are theoretical calculations concerning effects in water under different irradiation conditions.

\section{Recommendations}

Previous speculation (in reference to fig. 13) pointed out that the dependence of the measured absorbed dose rate on the thermistor electrical power dissipation may have been caused by increased thermal coupling (during irradition) between the thermistors, leads and connecting wires with their surroundings. The $c$-level (fig. 12) would then have dropped more than the $b$-level, and they may not have fully recovered in time after irradiation when extrapolations were made. The magnitude of this effect may be inherent in the exact thermal coupling in a particular detector. Regardless as to whether this was the cause, it would seem good constructional practice to have those temperature levels as low as possible for given thermistor power dissipations. The detector could be fabricated to increase the thermal coupling which may greatly attenuate the effect shown in figures 12 and 13. A portion of the leads and connecting wires was surrounded by air which has a lower thermal conductivity by a factor up to 20 compared to some adhesive materials. However, extreme caution must be used in applying such materials (preferably flexible). Those nonwater materials must be extremely thin. The calculated effect of the two $18 \mu \mathrm{m}$ films (fig. 6) should serve as a guide for the caution that must be used. ${ }^{13}$ It was also pointed out (Section 4) that theoretical calculations showed negligible effects caused by the beads and wires. Therefore, minute amounts of adhesive judiciously placed can still result in tolerably small excess heat generation. The material should also be of a slow-drying

\footnotetext{
${ }^{13}$ Being unaware of this need for caution was the reason for applying excessive silicone rubber to those elements in the first reported model of the water calorimeter [1] which was quickly assembled and beam tested within a month after conception of the idea of the instrument (the calculations were made a considerable time later). It was speculated in that report that the cooling effect after beam turn off (in figure 2 of that report) may have been caused by water convection. However, in the light of subsequent experimental work reported in this paper, that effect is believed to have been caused by heat conduction-excess heat conducted away that was caused by the excessive non-water adhesive material.
}

nature. Using a thin wire (or other suitable applicator), very small droplets of the adhesive could be applied in the regions of the greatest heat concentrations, on the top of the beads and along the Pt-Ir leads (and possibly on the lower film in their immediate vicinity). Per unit length, the ratio of thermal conductivities of the copper and $\mathrm{Pt}$-Ir wires used was $120 / 1$. After fastening the rings, air at constant pressure (or other mechanical means) should be applied to both sides of the films for a sufficient time to give good adherence and a minimal adhesive thickness between the beads, wires, and films. It would then be reasonable to expect that such a construction would also aid in making such a detector less sensitive to effects of changes in room barometric pressure as previously described and shown in figure 10 . It is worth repeating that the magnitude of that pressure effect became less noticeable as electrical power dissipations decreased. It was not noticeable at the $9 \mu \mathrm{W}$ level at which all the beam calibration measurements were made.

The cobalt- 60 measurements reported in this paper were within a 150-Gy accumulated absorbed dose at the point of measurement. Further investigations should be made at extended ranges including pre-irradiation of water beyond the $k G y$ region. Similar investigations should be carried out with other irradiation beams and a wide range of absorbed dose rates.

Although the data indicate that organic materials dissolved into the water from the plastic container do not seem to be a problem, it would still be good practice to minimize the amount of immersed plastic materials. Consideration should be given to constructing a container with its bottom and two opposite sides consisting of glass plates, and the other two sides consisting of stainless steel plates. The metal plates would serve a dual role as being the drift control electrodes containing drilled holes, beneath the water surface, through which the immersion heaters and signal feedthroughs would be mounted. The immersed tube, through which air is forced to agitate the water, should be glass.

\section{Summary}

Experience with the water calorimeter has proven that it can be placed into operation quickly. In this respect, it represents a considerable improvement over solid calorimeters requiring vacuum systems. The predominant goal of the NBS work in absorbed dose calorimetry was to develop means to quickly control or eliminate one of the most troublesome features of calorimeters that prevented their wider adoption as a practical laboratory instrument: the troublesome large and changing background drifts. Means to accomplish this were built into both the NBS graphite and water calorimeters. The 
drifts are quickly reduced to tolerable levels in the water calorimeter because of the drift control method of changing the power between two immersed electrodes. The water calorimeter also has additional desirable features of being relatively simple to construct and to operate. Furthermore, all its internal components are relatively rugged and easily accessible for possible repair or replacement. This is in striking contrast to painstakingly rebuilding delicate nested bodied structures of solid calorimeters once internal troubles occur. The operation of the water calorimeter was virtually trouble-free on every day of operation. In these respects, the first of two phases of investigation was essentially completed: that of overcoming the physical problems in making the calorimeter an effective and accurate instrument for measuring a temperature rise at a point along a temperature profile in water.

Finally, it should be noted that the instrument measured a temperature rise with more assurance than it measured absorbed dose, thus the second phase of the investigation is only in the initial stage: the investigation of irradiation effects produced by different beams, absorbed dose rates, and accumulated absorbed dose that may cause significant positive or negative heat defects at the point of measurement.

The primary conditions of the initial investigations reported here are for three-minute irradiations with cobalt- 60 gamma rays, a dose rate near $18 \mathrm{mGy} / \mathrm{s}$, and an accumulated dose of $150 \mathrm{~Gy}$. The mean of the standard deviations of daily sets of measurements was 0.6 percent. Satisfactorily reproducible results were obtained by using water with a wide range of impurities and with distilled water agitated with nitrogen or oxygen. The measured absorbed dose rate to distilled water was 3.5 percent higher than previous measurements with a graphite calorimeter that were converted to absorbed dose to water. Tests showed that there was no evidence of water convection.

\section{References}

[1] Domen, S. R. Absorbed dose water calorimeter, Med. Phys. 7 (2): 157-159; 1980 March-April.

[2] Domen, S. R. Absorbed dose water calorimeter, U.S. Patent Number 4,312,224; 1982 January.

[3] Domen, S. R. An improved absorbed dose water calorimeter, AAPM Meeting, Med. Phys. 8 (4): 552; 1981 July-August.

[4] Domen, S. R. Theory, performance, and measured results with an improved absorbed dose water calorimeter, Electron Dosimetry and Arc Therapy Symposium, Univ. of Wisconsin, 1981 September.

[5] ICRU Rep. No. 14, Appendix B. Washington, D.C.: ICRU Publications; 1969.

[6] Domen, S. R.; Lamperti, P. J. Comparisons of calorimetric and ionometric measurements in graphite irradiated with electrons from 15 to $50 \mathrm{MeV}$, Med. Phys. 3(5): 294-301; 1976 SeptemberOctober.
[7] Handbook of chemistry and physics, Cleveland: Chemical Rubber Publishing Co.

[8] Domen, S. R.; Lamperti, P. J. A heat-loss-compensated calorimeter: theory, design, and performance, J. Res. Nat. Bur. Stand. (U.S.) (Phys. and Chem.), 78A(5): 595-610; 1974 September-October.

[9] Pruitt, J. S.; Domen, S. R.; Loevinger, R. The graphite calorimeter as a standard of absorbed dose for cobalt -60 gamma radiation, $J$. Res. Nat. Bur. Stand. (U.S.) 86(5): 495-502; 1981 SeptemberOctober.

[10] Schmidt, E., On the application of the calculus of finite differences to heating and cooling problems in engineering, Frappls Festschrift, Springer, Berlin, p. 179 (1924).

[11] Binder, L., On the thermal conduction to the environment and the temperature increases of electrical machines, Wilhelm Knapp, Halle, Germany, p. 20 (1911).

[12] Ingersoll, L. R., Zobel, O. J., and Ingersoll, A. C., Heat conduction, Madison, WI, The University of Wisconsin Press, 209-213 (1954).

[13] Fishenden, M., and Saunders, O. A., An introduction to heat transfer. The Clarenden Press, Oxford, pp. 54-60 (1950).

[14] Patton, T. C., Graphical methods for temperature distribution with unsteady heat flow, Ind. Eng. Chem., 36(11): 990-996; 1944 November.

[15] Benedict, R. P., Transient heat flow, Electro-Technology, Sci. and Eng. series, 94-112; 1961 December.

[16] Schmidt, E., Thermodynamics, The Clarenden Press, Oxford, 428-433 (1949).

[17] Filimonov, A., Absorbed dose measurements in gelatin, Ph.D. Thesis (1973), Univ. of NC.

[18] McLaughlin, E., Thermal conductivity of liquids and dense gases, Chem. Rev. 64, 389-428 (1964).

[19] Velarde, M. G., and Normand, C., Convection, Sci. Am. 243(1): 93-; 1980 July.

[20] Carslaw, H. S., and Jaeger, J. C., Conduction of heat in solids, 2nd ed., Oxford, The Clarenden Press; 1959.510 p.

[21] Clark, F. M., Insulating materials for design and engineering practice, New York, John Wiley and Sons, Inc., pp. 421 and 530 (1962).

[22] Becker, J. A., Green, C. B., and Pearson, G. L., Properties and uses of thermistors-thermally sensitive resistors, Electrical Engineering, 1946 November.

[23] Clark, L. E., Report on the exactness of fit of thermistors to the equation $\log R=A+B /(T+\theta)$ and $\log R=A+B /(T+\theta)$ $+C T$, USASRDL Tech. Rep. No. 2168, U.S. Army Signal Res. and Dev. Lab., Fort Monmouth, NJ, (Jan. 1961).

[24] Theory and application of self-heated thermistors, V1210revised, Victory Engineering Corporation, Springfield, NJ.

[25] Draganic, I.G., and Draganic, Z. D., The radiation chemistry of water. New York and London: Academic Press; 1971. 242 p.

[26] Spinks, J. W. T., Woods, R. J. Radiation chemistry. New York: J. Wiley \& Sons; 1976. 504 p.

[27] Boyd, A.W., private communication (1981).

[28] Hart, E. J., and Fielden, E. M., Submicromolar analysis of hydrated electron scavengers, Advan. Chem. Ser. 50, 253-262 (1965).

[29] Marles, A. Ph.D. Thesis (1981), Univ. of Texas (Houston).

[30] Busulini, L. et al. Dosimetry of Co-60 r-rays by a simple calorimetric method, Int. J. Appl. Radiat. Isotop. 19(8): 657662; 1968 August.

[31] Kaarles, R., Report of the BIPM Working Group on the statement of uncertainties (1980).

[32] Cottens, E. Geabsorbeerde dosis kalorimetric bij hoge energie elektronenbundels en onderzoek van de izersulfaat dosimeter, Ph.D. Thesis, Univ. of Gent, Belgium, (1979-1980). 